\title{
Innovative approaches for controlling the material flow in sheet-bulk metal forming processes
}

\author{
Marion Merklein, Michael Lechner, Daniel Gröbel, Maria Löffler, Thomas Schneider, Robert Schulte, \\ and Philipp Hildenbrand*
}

Institute of Manufacturing Technology, Friedrich-Alexander-Universität Erlangen-Nürnberg (FAU), Egerlandstr. 13, 91058 Erlangen, Germany

Received 16 December 2015 / Accepted 2 January 2016

\begin{abstract}
Using sheet-bulk metal forming processes the application of bulk forming operations on sheet metals enables the manufacturing of functional components with local wall thickness variations. As these processes come along with a two- and three-dimensional material flow, the control of the material flow is crucial for ensuring a proper filling of functional elements and thus ensuring the components quality. Controlling the material flow can be achieved by different solutions: the local adaption of tribological conditions and the application of process adapted semi-finished parts. In this paper, both solutions as well as their general qualification in two sheet-bulk metal forming processes are presented.
\end{abstract}

Key words: Forming, Processes, Material flow

\section{Introduction}

One key aspect for the 21 st century is the saving of resources for reducing the greenhouse gas emissions and slowing down the climate change. Saving resources can be achieved by increasing the material efficiency [1] as well as improving mechanical properties and thus increasing the components quality. In the automotive industry for example, lightweight design can be achieved by integrating functional elements like gearings and thus reducing the number of individual parts with an additional improved material efficiency [2]. However, new processes or technologies have to be developed because these components cannot be manufactured by using state-of-the-art forming processes or result in long process chains or high costs [3]. The application of bulk forming operations on sheet metals, defined as sheet-bulk metal forming (SBMF), is a promising approach to meet these challenges [4]. Using processes defined within this class, complex functional components can be manufactured by shortened process chains with at the same time improved mechanical properties [4]. In sheet-bulk metal forming processes the interaction between areas of high and low deformation with a two- and three-dimensional material flow leads to new challenges. In this context, the control of the material flow is essential for ensuring a proper filling of the functional elements [5]. Directing the material flow can

*e-mail: philipp.hildenbrand@fau.de be achieved by two solutions presented in this paper. The local adaption of the tribological conditions as well as the application of process adapted semi-finished parts.

\section{Definition and classification of sheet-bulk metal forming}

In this section a short overview of the definition of sheetbulk metal forming is given.

Sheet-bulk metal forming is defined as forming of sheets with an intended three-dimensional material flow, which is typical for bulk forming processes [4]. This new process class includes conventional bulk forming operations that are applied on sheet metal and furthermore often combined and extended in their application. Additionally, they are oftentimes conducted in conjunction with conventional sheet forming processes. One central characteristic is given by the complex interaction of two and three-dimensional stress and strain states due to the bulk forming operations. This results in neighboring forming zones of high and low strains. All forming operations are applied on semi-finished parts of 1-5 mm thickness with the intention to form local shape elements projecting out of the plane, which are in the dimension of the sheet thickness [4]. Besides manufacturing of functional integration, SBMF can also be used to redirect material on sheets in order to produce semi-finished parts with tailored properties for 


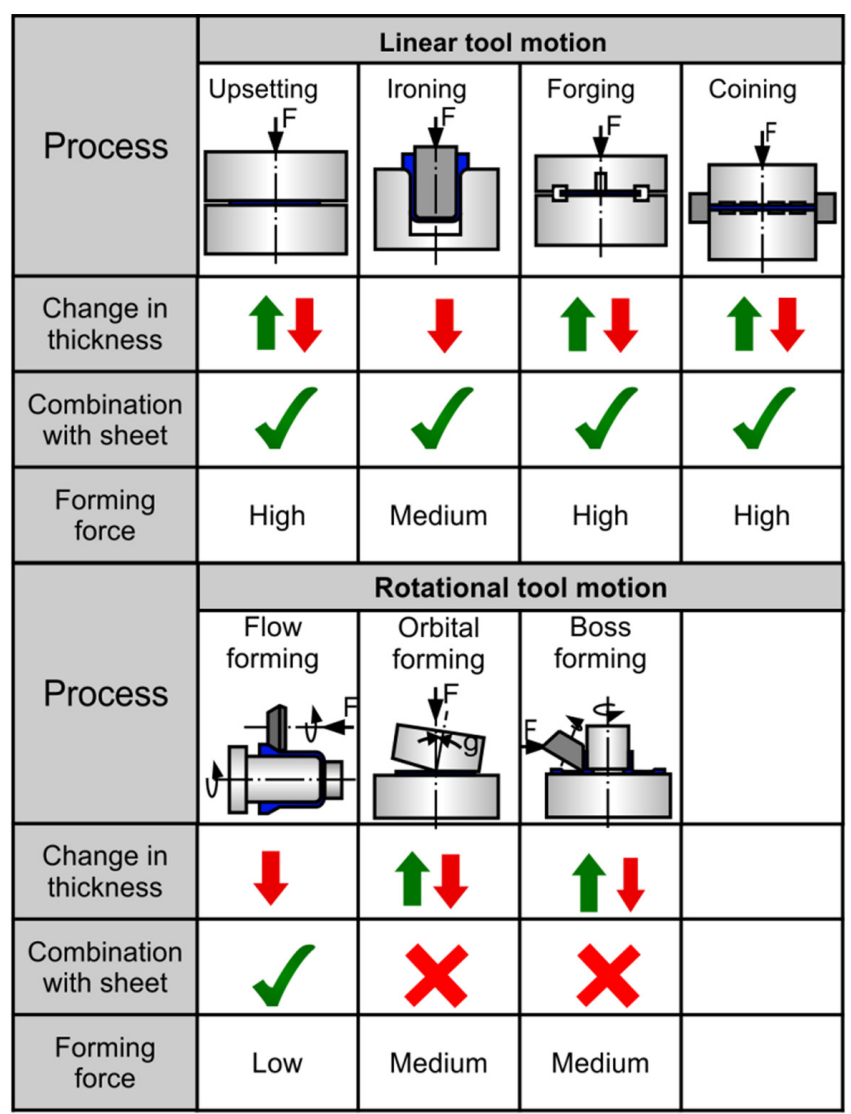

Figure 1. Process classification and characteristics of common sheet-bulk metal forming operations, according to the reference [7].

addressing the specific needs of differing amount of material in specific areas in SBMF processes.

In reference [6] forming processes are categorized regarding to the stress states during the forming operation. However, this classification is not applicable to sheet-bulk metal forming processes since characteristics of combined processes can merge in some cases [4]. Additionally, the geometry of the semi-finished parts in question is not taken into account. In order to solve this challenge, a classification that enables a distinction of possible processes by the tool motion in use is proposed in reference [4]. As Figure 1 shows, upsetting, ironing, forging and coining can be assigned to the group of linear motions whereas rotational movement can be found in flow forming, orbital forming and boss forming. Furthermore, all processes can be described by the resulting change in sheet thickness, the known application in SBMF, the possibility of combinations with sheet forming operations and by the level of forming force. Process forces are particularly dependent on the effective contact area between workpiece and tool during the forming operation. High contact areas result in high process forces, whereas small contact areas demand less force. Due to this circumstance upsetting, forging and coining possess the highest force demands due to their typically large contact areas. One strategy to overcome this challenge is the use of incremental forming processes like orbital forming or flow forming. Such processes are characterized by a small but moving contact and forming zone.
As listed in Figure 1, it is possible to both locally reduce or heighten sheet thickness in most sheet-bulk metal forming processes. Additionally, a combination with conventional sheet forming operations is predominantly possible. The circumstance that both aspects apply to forging and upsetting makes those operations particularly promising methods if complex sheet products of high functional integrations have to be produced. However, a typical characteristic of functional elements are their small dimensions in comparison to the total dimensions of the part. Subsequently, the forming of such structures results in complex locally restricted three-dimensional forming zones. These zones typically possess high plastic strains that are surrounded by large areas of non-strain hardened material. Due to this interrelation, the material flow during the forming operation gets progressively more pronounced in direction of the strain gradient and impedes the forming of the functional elements. Therefore, controlling the material flow in sheet-bulk metal forming processes is crucial for the proper forming of functional elements. This can be achieved by different conventional approaches such as for example adapting the tool design by the application of drawbeads. However, this solution results in a change of the final geometry of the component. Avoiding this and furthermore considering the characteristics of SBMF processes, new and innovative solutions and their specific adaption for the needs of SBMF processes are necessary. These solutions are presented in Section 5 for two developed sheetbulk metal forming processes listed in Figure 1 and presented in a subsequent section with focus on the necessity of controlling the material flow.

\section{Materials and methods}

In this section, a short overview of the applied materials and methods for characterizing the manufactured components shall be given as these were used for all of the investigations presented in the following part of this paper.

\subsection{Materials}

The workpiece materials used for the investigation in the framework of this paper were the mild deep drawing steel DC04 and the high-strength steel DP600. The corresponding material properties, which were determined in a layer compression test, are depicted in Figure 2. The measured flow curves were extrapolated using the Hockett-Sherby equation.

Numerical investigations in the framework of this paper were carried out with the commercial software Simufact Forming 12. The isotropic von Mises material model with the experimentally determined and extrapolated flow curves was used.

As a lubricant for all processes, the wax-based Beruforge 150 DL from the Carl Bechem GmbH was used.

\subsection{Component characterization}

The manufactured SBMF-components were analyzed by their geometric and mechanical properties. 


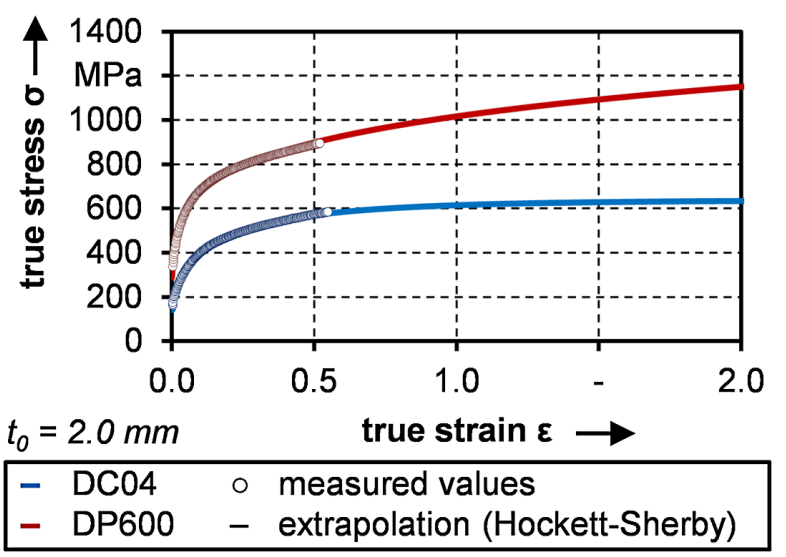

Figure 2. Material properties of DC04 and DP600 determined in the layer compression test.

For the geometric dimensions, the manufactured components were measured by using two different systems: the tactile three-dimensional coordinate measuring machine Leitz PPM 654 and the optical 3D-scanner ATOS Core 300 from the GOM $\mathrm{mbH}$. The tactile measuring enables a precise two dimensional contour measurement which can be used for calculating the sheet thickness. By using the optical measurement system a digitized model of the component can be determined. This is necessary for analyzing the filigree functional elements in terms of their die filling or height.

The mechanical properties of the components were analyzed by measuring the Vickers hardness using the Fischerscope HM2000 system from the Helmut Fischer GmbH \& Co. $\mathrm{KG}$ with a measuring force of $500 \mathrm{mN}$.

For analyzing the surface of a workpiece or tool, two systems were used. The topography was determined using a confocal lasers canning microscope Keyence VK-X200. Additionally, the roughness is determined by tactile stylus measurements using a Mahr MarSurf GD 120.

\section{Examples of SBMF processes}

In SBMF the complex interactions of two- and threedimensional stress and strain states lead to challenges for ensuring a proper quality of the manufactured components as functional elements are not formed completely. Thus, controlling the material flow is crucial for ensuring the desired product quality. In this section, two SBMF processes and their needs regarding a controlled material flow due to an insufficient die filling of functional elements are presented.

\subsection{Deep drawing and upsetting}

The processes deep drawing and upsetting are well established in the manufacturing industry. However, there is no sufficient fundamental research on the combination of these processes and on their application to sheet metal. To gain process understanding a process combination of deep drawing and upsetting was developed at the Institute of Manufacturing Technology in Erlangen and enables the forming of parts with

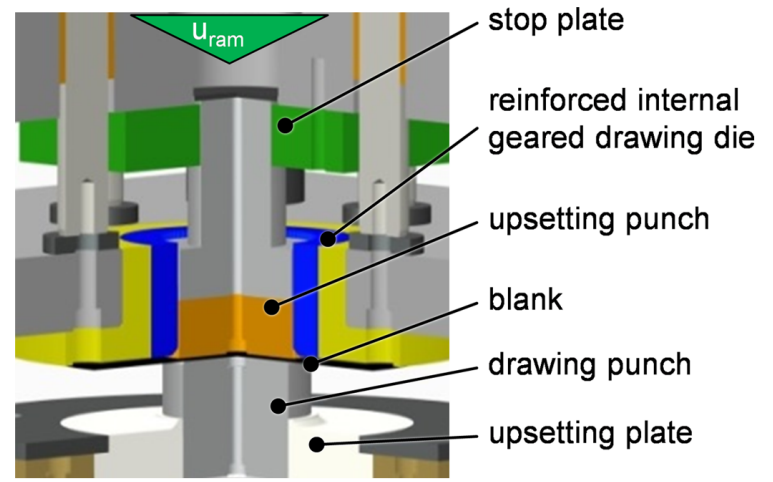

Figure 3. Tool set-up for the combined deep drawing and upsetting process [8].

functional elements, such as gear teeth, out of sheet metal [8]. The functional elements are thick-walled, so the thickness of the functional elements is higher than the initial sheet thickness of $t_{0}=2.0 \mathrm{~mm}$. The tool concept with the relevant tool components is shown in Figure 3.

The single-stage process is performed on the triple-acting hydraulic press Lasco TZP 400/3 with an additional hydraulic cylinder. In the first process phase the circular blank is deep drawn to a cup which is upset in the second phase. The tool concept consists of an upper and a lower die. The drawing die and the upsetting punch are part of the upper die whereas stop plate and drawing punch belong to the lower die. In the initial position, the blank is positioned on the drawing punch and axially clamped by the upsetting punch. The clamping force is set to $F_{\mathrm{c}}=400 \mathrm{kN}$. The drawing die moves downwards by $u_{\text {ram }}$ over the drawing punch and forms the cup. On the outer wall of the cup radial tensile stress occurs while the inner wall is subjected to compressive stress. With ongoing movement, the drawing die is positioned on the stop plate and the ram force is directed into the upsetting punch by a mechanical stop. As the increasing force $F_{\mathrm{U}}$ exceeds the replacement force of the drawing die the upsetting operation begins. This causes a variation in stress. Most of the radial tensile stress is overlaid by compressive stress as the cup height $h$ is reduced by upsetting. As soon as the compressive stress exceeds the yield stress of the workpiece material, the material flows radially into the cavity of the functional elements. Due to the fact that the process is performed force bound, the cup height is reduced until the set force $F_{\mathrm{F}}$ is reached. The maximum forming force is $F=4,000 \mathrm{kN}$, which is the maximum force of the hydraulic press. The modular tool concept also allows the manufacturing of cups with thin- and thick-walled functional elements, such as open carriers and gear teeth as well as their combination. For this paper the focus will be on a geared component with a circumferential external gearing of 80 teeth. The corresponding geometric dimensions are shown in Figure 4 with a cross section of the gear shape in Figure 4a and the resulting target geometry in Figure $4 \mathrm{~b}$.

Due to areas without tool contact, two modes of failure occur in the upsetting process, as presented in Figure 5. After the deep drawing, the thin cup wall buckles as the drawing punch has a maximum gap of $u_{\mathrm{c} \text { max }}=3.65 \mathrm{~mm}$ to the die cavity in the tooth base, which is significantly wider than the 
(a)

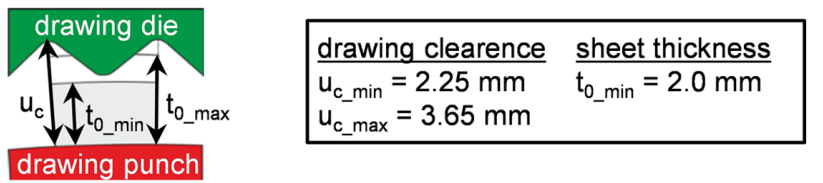

(b)

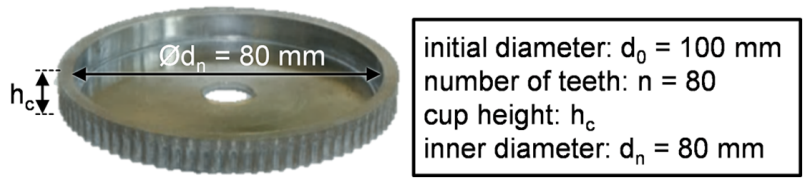

Figure 4. (a) cross-section of the gear shape and (b) target geometry and blank layout [8].

(a)

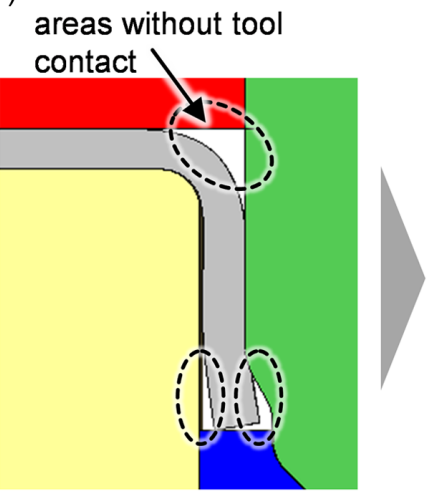

(b)

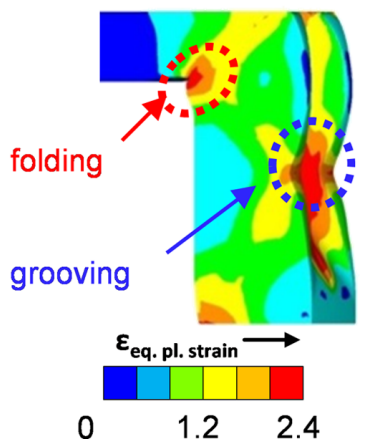

Figure 5. Areas without tool contact after (a) deep drawing and (b) failure modes after upsetting [9].

sheet thickness. This leads to a grooving in the external gearing and a folding at the drawing radius.

For the standard initial diameter of $d_{0}=100 \mathrm{~mm}$ and initial sheet thickness of $t_{0}=2.0 \mathrm{~mm}$, the final component shows one circumferential groove due to buckling of the wall, see Figure 6a. Using blanks with a higher initial sheet thickness $t_{0}=2.6 \mathrm{~mm}$ and the same initial diameter $d_{0}=100 \mathrm{~mm}$ the groove can be reduced. However, the higher initial sheet thickness leads to a higher thickness of the cup bottom as shown in Figure $6 \mathrm{~b}$. As during upsetting, the free space is filled with material from the cup wall a folding occurs. The grooving area shows a strain hardening due to the material plasticisation. The increasing contact zone in the gear cavity leads to higher friction. In combination with the strain hardening in this area of the part, the material flows into the unhardened bottom of the cup. The thickening of the bottom contradicts the aim of lightweight construction.

The inadequate material volume in the area of the gearing make tailored surfaces and tailored blanks appear as a promising approach to improve the geometrical properties and thus the quality of the final part.

\subsection{Forward extrusion}

Another example for a SBMF process is forward extrusion on sheet metals. However, in contrast to upsetting, functional

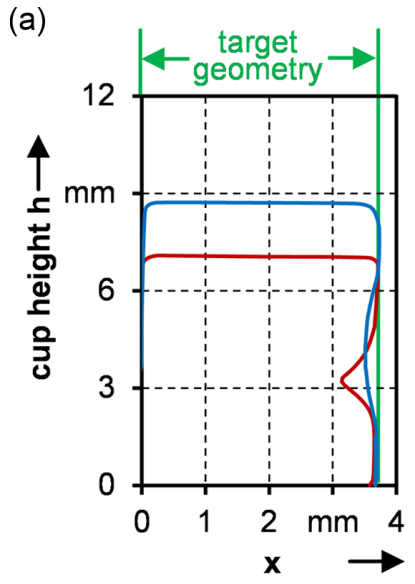

(b)

$$
-\mathrm{t}_{0}=2.0 \mathrm{~mm}-\mathrm{t}_{0}=2.6 \mathrm{~mm}
$$

Figure 6. Influence of the sheet thickness on the (a) wall geometry and (b) bottom thickness of the final cup.

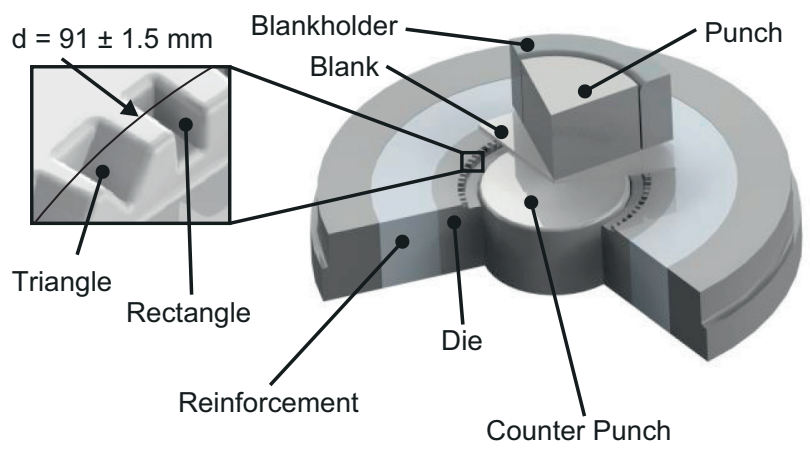

Figure 7. Process design of a forward extrusion process [10].

elements can be formed on flat sheet surfaces and in direction of the blank normal. The process variant is depicted in Figure 7. It enables the forming of circular arranged and alternating rectangular and triangular elements on a blank of $d=120 \mathrm{~mm}[10]$.

This process variant has been firstly described in reference [11] in combination with deep drawing and has been extended in reference [12] with the introduction of geometrically differing elements to increase the components complexity. In order to perform the forming operation, a circular blank is placed centrally on the die. Subsequently, the punch initiates the forming of the blank into the corresponding cavities that have the negative geometry of the elements in question. In addition, a blank holder, as well as a counterpunch is used to impede potential bulging of the blank. To illustrate the influence of the potential forming without counterpunch an exemplary part is pictured in Figure 8. The bulging is a direct result of the upsetting of the blank in the area between the cavities, which results in a radial material flow from the elemental forming area in direction of the blank center.

In principle, arbitrary geometries without undercuts can be formed from flat surfaces. However, in practical use there are challenges that limit the possible element dimensions. 


\begin{tabular}{|ll|}
\hline DC04 & Blankholder: $F_{B H}=360 \mathrm{kN}$ \\
$t_{0}=2.0 \mathrm{~mm}$ & Counterpunch: $F_{C}=0 \mathrm{kN}$ \\
Stroke: $\mathrm{s}=1.7 \mathrm{~mm}$ & Blank diameter: $\mathrm{d}_{0}=120 \mathrm{~mm}$ \\
Punch force: $\mathrm{F}=1000 \mathrm{kN}$ & \\
\hline
\end{tabular}

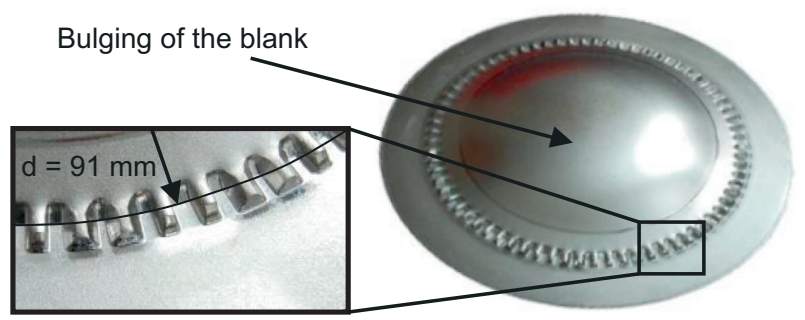

Figure 8. Resulting workpiece with functional elements.

Although the actual forming area of the elements is small in relation to the total blank area, high punch forces are necessary to enable the simultaneous forming of all desired elements in one step. Using a high-strength steel DP600 blank with a initial thickness $t_{0}=2 \mathrm{~mm}$ and a punch stroke of $s=1.7 \mathrm{~mm}$ demands a press force of $F=1,660 \mathrm{kN}$. Another restriction can be found in the high tool loads that are typically present in SBMF forward extrusion processes. Due to the high punch forces, tool stresses particularly in the cavity edges are challenging to current tool steels and technologies. In the example above, the maximum possible reinforcement regarding the ultimate compressive strength of the tool steel ASP2023 (1.3344) is utilized. However, simulated results with a validated simulation model [12] show, that tensile stresses can locally reach values of up to 1,500 MPa despite using the relatively low strength steel DC04 of $t_{0}=3 \mathrm{~mm}$, which is the maximum sheet thickness formed by this process, initial thickness and a punch stroke of $t=2.7 \mathrm{~mm}$. Hence, especially with high strength materials, available tool load will limit the total process stroke and therefore the maximum possible element dimensions. Furthermore, the maximum element height is determined by the maximum punch stroke and therefore by the initial sheet thickness of the blank.

Another influence on the element height results in the insufficient filling of the cavities due to radial material flow. Thus, a major challenge of this process class is the control of the material flow in the sheet plane. Since the forming zone around the cavities is small in comparison to the remaining blank area, a distinctive strain gradient develops with increasing punch stroke. Due to this circumstance, the radial material flow in the sheet plane gets progressively dominant and leads to an underfilling of the cavities and bulging of the blank. As a result, the forming of the elements is incomplete even at high punch strokes. Figure 9 demonstrates this occurrence by means of the radial flow rate at a punch stroke of $t=1.7 \mathrm{~mm}$.

As can be derived from the simulated results, the cavity filling behavior is incomplete in both the rectangular and in the triangular cavity. The shape is dependent on the material flow in the cavity itself, which in turn is dependent on the geometrical shape of the cavities [12]. Besides individual die filling, the material flow is of importance in regard to the resulting macroscopic blank geometry, the bulging of the blank when forming without a counterpunch.

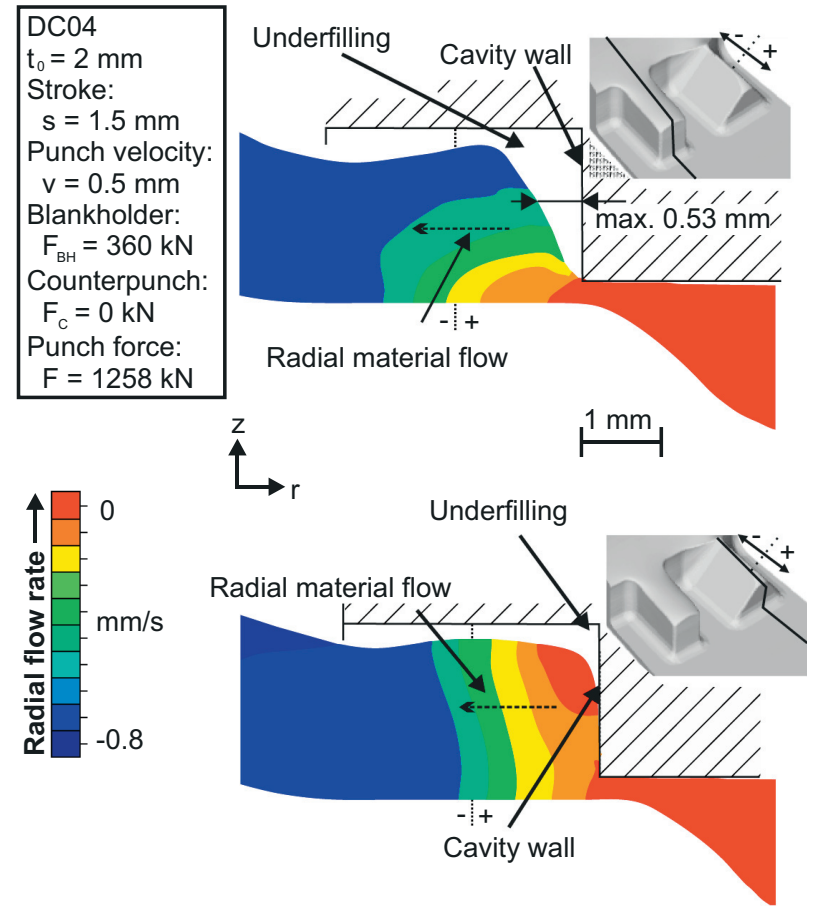

Figure 9. Underfilling of the cavities due to radial in-plane material flow at $s=1.5 \mathrm{~mm}$.

Besides conventional approaches for improving the die filling of functional components such as increasing the forming force with negative aspects like higher tool loads or using blanks with a higher initial sheet thickness and thus more weight as in the combined deep drawing and upsetting process, there are alternative and innovative approaches to achieve this target. Two of them, the local modification of the tribological conditions, as well as the application of process adapted semi-finished parts are presented in the following.

\section{Innovative solutions for controlling the material flow in sheet-bulk metal forming processes}

As mentioned in Section 4, SBMF processes are characterized by an interaction of forming zones of high and low strains and locally varying two- and three-dimensional stress and strain states [4]. This is explained by the fact that the manufactured components often contain bulk formed features, like carrier elements or gearings, as well as functional areas manufactured by sheet forming operations such as deep drawing or collar forming. Due to the combination of sheet and bulk forming operations within one single SBMF process, contact normal stresses with values below $100 \mathrm{MPa}$ can occur as well as local areas with values up to 2,500 MPa which are typical for bulk forming operations [13]. These process characteristics significantly influence the material flow during forming, what often results in a reduced product quality in terms of geometrical accuracy as shown in Section 4. Thus, the identification of methods which are aimed to control the material flow is of major importance to guarantee an acceptable process result. 


\subsection{Locally adapted tribological conditions to influence the material flow in SBMF}

A promising approach to meet to control the material flow is the adaption of the tribological conditions in the contact area between tool and workpiece. Former investigations already analyzed the interaction of material flow and tribological conditions and the potential to influence the material flow using an adaption of the friction [14].

The modification of the tribological conditions between workpiece and tool are enabled by an adjustment of the lubricant and the surface properties of the workpiece and/or the tool. The influence of lubricants, in dependence of their properties, on the tribological conditions is investigated in a former study [15]. To modify the tribological conditions by an adjustment of the surface properties the surface topography and the chemical composition are major influencing factors. The connection of surface properties and frictional behavior is subject of numerous investigations. Exemplarily, in reference [16] the effect of adapted tool surfaces on the tribological conditions using micro milling has been shown.

Based on the process characteristics in SBMF a global adaption of the friction conditions between workpiece and tool is not expedient. To fully use the potential of adapted tribological conditions for this kind of processes, the adaptions need to be adjusted locally to the respective boundary conditions. The required local adaption using different lubricants is complicated due to the mainly liquid consistency of lubricants and the heavily practicable local application. Thus, the local adaption of the surface properties of the tool and/or the workpiece is a more efficient way for the application in SBMF processes. These so-called tailored surfaces are a suitable approach to influence the frictional behavior in SBMF due to the adapted surface properties. For an appropriate selection, adapted to the respective boundary conditions, methods for an increase as well as a reduction of the friction conditions are needed.

Based on the fundamental requirements regarding the tribological conditions in SBMF, milled [17], micro structured and coated surfaces [18] could be identified in former investigations as suitable methods for tool-sided adaptions. The application of coatings on the tool surface is aimed to influence the chemical composition of the tool surface and normally leads to a reduction of the friction due to chemical interaction of the coating and the used lubricant. The usage of milling or micro structuring processes focuses on an adaption of the surface topography and thus the roughness. In general, an increase of the roughness leads to an increase in friction conditions due to an enhanced catch of the roughness peaks [19]. For the workpiece-sided modification micro structuring and abrasive blasting of the surface are suitable methods to adapt the surface topography and thus to generate a gradient in friction conditions [20]. The application of deterministic structures by micro structuring is aimed to generate lubrication pockets and thus to reduce friction. The increase of the surface roughness by abrasive blasting leads to an increase of friction by an enhanced catch of the roughness peaks. The combination of a workpieceand a tool-sided modification can additionally strengthen the effect of the surface modification on the tribological conditions.

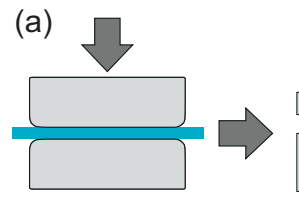

(b)

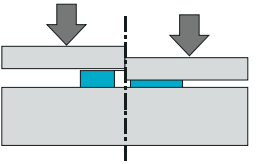

(c)

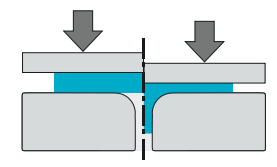

Figure 10. Test principle of (a) strip drawing test, (b) ring compression test and (c) pin extrusion test.

For a comprehensive analysis of the influence of tailored surfaces on the tribological conditions laboratory friction tests are used. To determine the friction in SBMF processes, a test methodology consisting of three different tests was developed. This is necessary to take all load and forming conditions, which can occur in SBMF processes, into account. Figure 10 illustrates the test principles of the three laboratory friction tests. The strip drawing test is applied to determine the tribological behavior of tailored surfaces under sheet forming conditions and thus under low contact normal stresses and high sliding velocities. To analyze friction conditions under bulk forming conditions, the ring compression test is used. This test is aimed to model friction conditions which occur during conventional upsetting processes. Additionally the pin extrusion test, as a laboratory test for bulk forming conditions, was chosen. The pin extrusion test combines an upsetting and a forward extrusion process and is used due to the fact that the forming conditions are close to those which appear when features are formed out of the sheet plane. A suitable test has to be chosen based on the forming and load conditions which occur in the investigated SBMF process.

To demonstrate the tribological effectiveness of tailored surfaces two different surface modifications will be exemplarily evaluated regarding the interaction of surface properties and friction conditions. For this investigation the ring compression test was chosen because of the application in Section 6.1.1. The forming and load conditions of the two investigated SBMF processes are well described by the ring compression test as laboratory friction test. Another benefit of this test is the good accessibility of the tool surface and thus the easy applicability of the tool-sided tailored surfaces. For a comprehensive analysis surface modifications of tool and workpiece are investigated. As tool material the powder metallurgical tool steel ASP2023 with a hardness of $60 \pm 1 \mathrm{HRC}$ was applied. This tool steel is commonly used steel for this kind of process.

For the workpiece-sided adaption abrasive blasting was chosen as an efficient way to adapt the surface topography. The blasting treatment is carried out on the blasting cabinet ATLAS SBC 350 using an $\mathrm{Al}_{2} \mathrm{O}_{3}$ abrasive with a grit size between 400 and $600 \mu \mathrm{m}$ and a Mohs hardness of 9. Compared to the blasted surface, the initial surface, which is a conventional EDT surface, has a lower profile depth. The average roughness $R_{\mathrm{a}}$ of the blasted surface amounts to $2.45 \pm 0.16 \mu \mathrm{m}$, see Figure 11 . In contrast, the untreated surface has a lower $R_{\mathrm{a}}$ value of $0.99 \pm 0.03 \mu \mathrm{m}$. Additionally, the application of blasting processes on the workpiece surface results in an increased number of roughness peaks. That should lead to an enhanced catch of the roughness peaks. In consequence the changed surface properties regarding topography and roughness should result in higher friction conditions. 

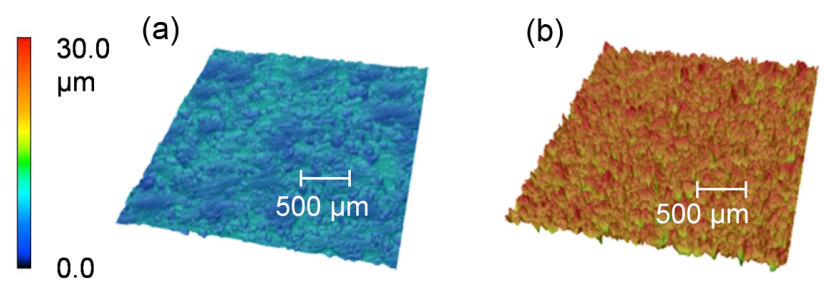

Ra: $1.02 \pm 0.08 \mu \mathrm{m}$

$2.45 \pm 0.16 \mu \mathrm{m}$

\begin{tabular}{|llll|}
\hline \multicolumn{3}{l}{ Topography } & \multicolumn{2}{l|}{ Roughness } \\
\multicolumn{3}{c|}{ Confocal laserscanning } & MarSurf GD 120 \\
Lens & $20 \mathrm{x}$ & $\lambda \mathrm{s}$ & $2.5 \mu \mathrm{m}$ \\
$\lambda \mathrm{s}$ & $2.5 \mu \mathrm{m}$ & $\lambda \mathrm{c}$ & $0.8 \mathrm{~mm}$ \\
$\lambda \mathrm{c}$ & $0.8 \mathrm{~mm}$ & $\mathrm{n}_{\text {Measure. }}$ & 5 \\
\hline
\end{tabular}

Figure 11. Workpiece-sided surface properties of (a) initial surfaces and (b) blasted surface.

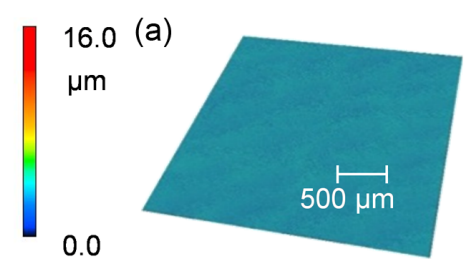

Ra: $0.24 \pm 0.03 \mu \mathrm{m}$ (b)

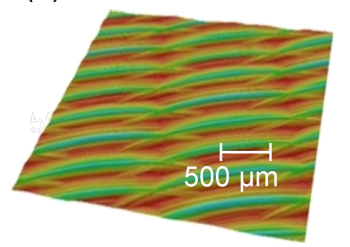

$2.41 \pm 0.34 \mu \mathrm{m}$

\begin{tabular}{|llll|}
\hline \multicolumn{3}{l}{ Topography } & \multicolumn{3}{l|}{ Roughness } \\
\multicolumn{3}{c|}{ Confocal laserscanning } & MarSurf GD 120 \\
Lens & $20 \mathrm{x}$ & $\lambda \mathrm{s}$ & $2.5 \mu \mathrm{m}$ \\
$\lambda \mathrm{s}$ & $2.5 \mu \mathrm{m}$ & $\lambda \mathrm{c}$ & $0.8 \mathrm{~mm}$ \\
$\lambda \mathrm{c}$ & $0.8 \mathrm{~mm}$ & $\mathrm{n}_{\text {Measure. }}$ & 5 \\
\hline
\end{tabular}

Figure 12. Tool-sided surface properties of (a) initial surface and (b) milled surface.

Another possibility to adapt the tribological conditions is given by the adaption of the workpiece surface. Exemplarily, the influence of milled tool surfaces on the friction will be presented within this analysis. To investigate the influence of milling process a high-feed milling process was chosen as an efficient way to adapt the topography of the investigated tool material. This kind of milling processes combine high removal rates with conventional cutting speed to machine free-formed surfaces [21]. Figure 12 illustrates a milled surfaces compared to the initial tool surface which is lapped. The milling process was carried out on a 5 -axis machining center Deckel Maho DMU 50 eVolution. As feed per tooth rate $f_{\mathrm{z}} 0.251 / \mathrm{mm}$ and as width of cut $a_{\mathrm{e}} 1 \mathrm{~mm}$ were chosen. The chosen strategy was a superimposed up and down milling. The surface topography shows that the application of a high-feed milling process leads to an adaption of the topography and an increase in roughness. The lapped surface has a lower profile depth and average roughness height with $R_{\mathrm{a}} 0.25 \pm 0.03 \mu \mathrm{m}$. Compared to that the average roughness height of the milled surface amounts $2.41 \pm 0.34 \mu \mathrm{m}$. This higher roughness should lead to a restrained material flow and thus to higher friction.

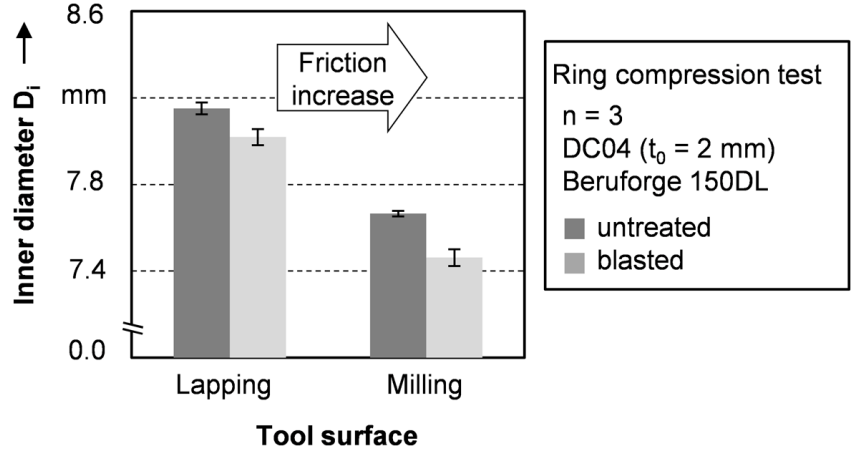

Figure 13. Results of the ring compression test.

For the investigation of the tribological conditions of the workpiece- and tool-sided tailored surfaces presented in Figures 11 and 12 using the ring compression test an adapted workpiece geometry was used. The adaption is based on the specific forming conditions in SBMF. With the help of a numerical feasibility study, the highest sensitivity regarding a change in tribological conditions was identified for an inner diameter of $d_{\mathrm{i}}=9 \mathrm{~mm}$, an outer diameter of $d_{\mathrm{o}}=15 \mathrm{~mm}$ and an initial sheet thickness of $t_{0}=2 \mathrm{~mm}$ [21]. Based on the resulting workpiece geometry after a punch stroke of $1 \mathrm{~mm}$, the friction conditions are qualitatively determined. The smaller the resulting inner diameter, the higher the friction is. The experimental investigations were carried out on a hydraulic deep drawing press Lasco $100 \mathrm{SO}$ with a ram speed of $1 \mathrm{~mm} / \mathrm{s}$. To guarantee a statistical coverage three workpieces were tested for each test series.

Figure 13 illustrates the results of the ring compression test for the surface modifications compared to the initial workpiece and tool surfaces. The diagram reveals that the usage of blasted workpiece surfaces leads to an increase in friction for the initial tool surface and the modified tool surface. Thus, higher roughness of the workpiece increases friction. The application of milled structures on the tool surface leads to a significant increase in friction compared to the lapped initial tool surface. Thus, the presented modifications of tool and workpiece surface are suitable methods to influence the tribological conditions. The roughness increase is suitable to reach an increase in friction conditions. Additionally, it can be stated that a combination of blasted workpieces and milled tools leads to the highest friction. Thus, the combination of such adapted tool and workpiece surfaces strengthens the effect on the friction conditions.

The investigations reveal that the adaption of the surface properties of tool and workpiece surfaces are suitable methods to influence the tribological conditions. Based on the respective process requirements these adaptions can thus be chosen for an application in SBMF process to prove the effectiveness in terms of an improved process result.

\subsection{Process adapted semi-finished parts for directing the material flow}

Besides the local modification of tribological conditions, the application of process adapted semi-finished parts, 
so called tailored blanks for controlling the material flow in sheet-bulk metal forming is another possible solution. Tailored blanks are designed specifically for their field of application by adapting the geometric and mechanical properties [22]. In contrast to other kinds of tailored blanks such as tailor welded blanks, tailored blanks manufactured by forming processes do not have a heat affected zone but show an uninterrupted grain orientation due to the forming process.

One possible process in SBMF to manufacture tailored blanks is orbital forming. First presented as a cold bulkforming process in reference [23], orbital forming enables the enhancement of process limits such as the forming force compared with conventional upsetting. Regarding its industrial application, orbital forming is used for manufacturing axial symmetric near net-shape components like bevel gears [24] or gear wheels [25]. In orbital forming, a tilted upper die with the typical tumbling motion leads to a reduction of the contact zone between tool and workpiece of up to $70 \%$ compared with conventional upsetting [26]. As a result, lower forming forces up to $90 \%$ are possible [26]. The tumbling motion and thus the continuously moving contact zone leads to the rolling of the workpiece under compressive stresses with a locally restricted forming zone [27] causing an inhomogeneous tangential and radial and additional time dependent distribution of stresses on the workpiece side which is in contact with the rotating die [28]. In contrast, the other side of the workpiece shows a predominantly homogeneous distribution [28]. The rotating die leads to a radial and tangential material flow in the workpiece during the orbital forming process with the tangential one dominating due to the upper surface of the workpiece being in contact with the rotating die resulting in the tangential deformation [28]. The tangential material flow in orbital forming leads to a thinning as well as thickening of the workpiece whereas in upsetting a material flow in radial and axial direction results in a widening and thinning of the workpiece [29].

Besides the kinematics, the material flow is influenced by the friction conditions between workpiece and tool. For conventional upsetting, the radial material flow is restricted resulting in higher contact normal stresses towards the center of the workpiece. In contrast, the smaller contact area in orbital forming leads to less locally varied contact stresses benefiting the material flow [30]. However, the differences in contact stresses are higher between areas of contact and non-contact.

Additionally, in upsetting the friction between tool and workpiece leads to a slower material flow near the surface resulting in a barreling of the workpiece with the highest plastic deformation in the workpiece center [31]. For orbital forming, the three-dimensional material flow and rotating contact area resulting in a greater outer diameter of the workpiece on the contact side between workpiece and rotating die, leading to the so-called "mushroom-effect" [32]. However, this effect is primarily of interest when applying orbital forming on bulk metal as these parts normally have a higher initial thickness.

In contrast to the industrially established application of orbital forming in bulk forming operations, the tooling concept presented in reference [33] enables the forming of sheet metal by orbital forming. Its tooling concept is presented in detail in reference [33] and shown in Figure 14. It enables the manufacturing of tailored blanks with locally varying sheet thickness

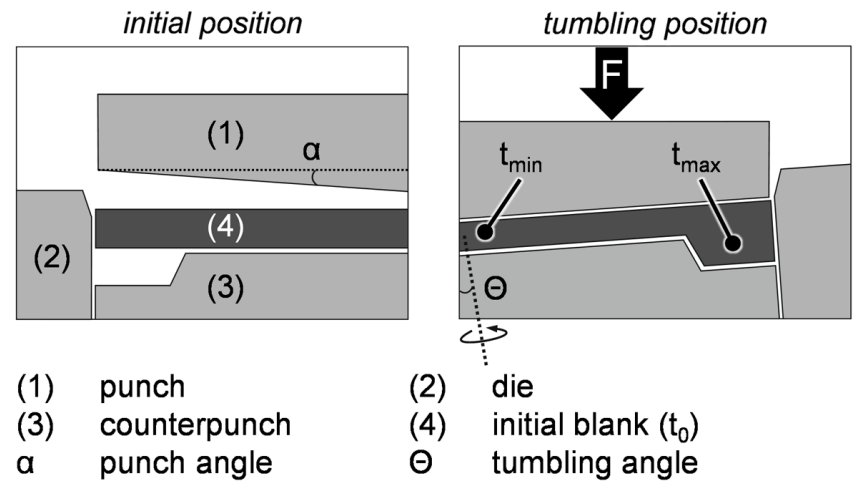

Figure 14. Tool design for manufacturing tailored blanks by orbital forming [34].

distribution. These tailored blanks can be used in subsequent processing for manufacturing thin-walled components with an external gearing [9]. In this tooling concept the conical upper punch with a punch angle of $\alpha=0.5^{\circ}$ transmits the press force $F$ in the tool system whereas the lower tool parts are applying the typical tumbling motion at a cycle speed of $v=0.5 \mathrm{~s}^{-1}$. During the process the material is transferred radially from the inner center towards the outside area. By having a negative imprint of the desired target geometry in the counterpunch the local thickening can be achieved. The die prevents a radial extension of the material, thus benefiting the material flow in the die cavity of the target blank layout in the counterpunch.

During the orbital forming process three characteristic process phases can be distinguished which are linked to the tumbling angle $\Theta$. The angle defines the tilting of the counterpunch and die. Starting at $\Theta=0^{\circ}$, the tumbling angle is ramped up to the maximum angle $\Theta=1^{\circ}$ in the first phase $U_{\mathrm{u}}$. In the second phase $U_{\mathrm{c}}$ the tumbling angle is held constant at $\Theta=1^{\circ}$. In the third phase $U_{\mathrm{d}}$ the tumbling angle is reduced back to its starting value of $\Theta=0^{\circ}$. In each phase the number of tumbling cycles can be set individually with at least one cycle required.

By using counterpunches with diverse negative imprints, different tailored blank geometries can be manufactured. For this investigation, a rotational symmetric geometry with a local thickening zone of $h=0.9 \mathrm{~mm}$ in the thickened outer area between $42 \leq r \leq 50 \mathrm{~mm}$ was used. The transition zone towards the thickening zone inclines between $40 \leq r \leq 42 \mathrm{~mm}$ with a rounding radius of $r=2.0 \mathrm{~mm}$. The geometric dimensions are depicted in Figure 15. This geometry is suited for the subsequent processing of the tailored blanks and manufacturing cups with a circumferential external gearing in both of the presented SBMF-processes shown in Section 4 as the local thickening area equals the area of the then formed functional elements.

Applying the standard process parameters determined in previous investigations [35] for DC04 using a process force of $F=3,000 \mathrm{kN}$ and five cycles in each process phase, a tailored blank with the sheet thickness distribution depicted in Figure 16a can be realized. The material is reduced in the inner area down to $t=1.6 \mathrm{~mm}$ and thickened in the outer die area up 


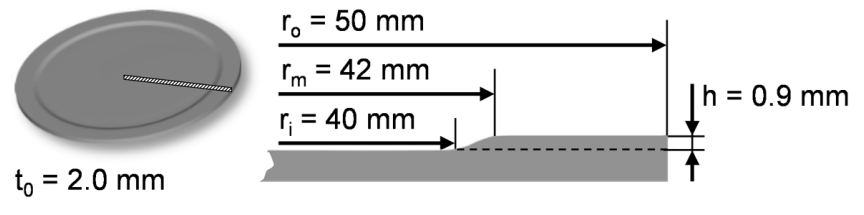

Figure 15. Tailored blank geometry. (a)

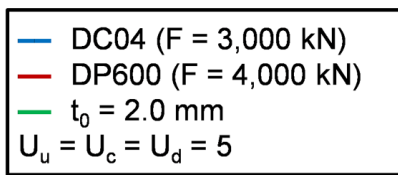

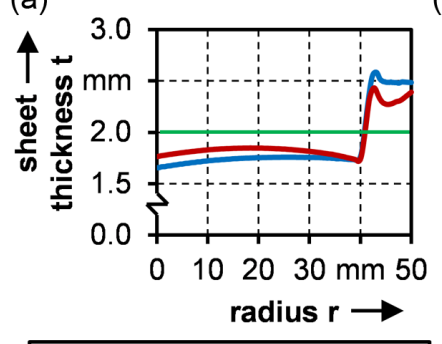

(b)

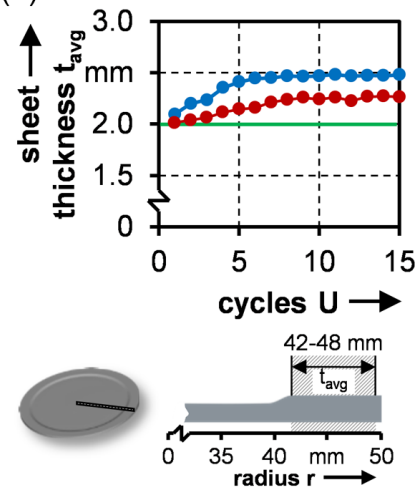

Figure 16. Geometric properties for tailored blanks out of DC04 and DP600 with (a) final radial sheet thickness distribution and (b) average sheet thickness during the process time.

to $t=2.5 \mathrm{~mm}$. Applying the same number of tumbling cycles on the DP600 steel with a higher process force of $F=4,000 \mathrm{kN}$ necessary due to the higher strength of the DP600 [34], a maximum local thickening of only $t=2.3 \mathrm{~mm}$ can be achieved. The higher process force, which is the maximum available press force, and the same number of tumbling cycles in each phase does not result in the same geometric dimensions as for DC04 due to the higher strength and differing formability of the DP600.

The average maximum sheet thickness $t_{\text {avg }}$ in the thickened outer die area was detected for each tumbling cycle and is shown in Figure 16b. For both materials an increase of $t_{\mathrm{avg}}$ in the first five tumbling cycles, the phase $U_{\mathrm{u}}$ with increasing tumbling angle, can be detected followed by a saturation in $U_{\mathrm{c}}$. During the ramp down of the tumbling angle there is no further increase or decrease of the sheet thickness.

An explanation for the increase of the average sheet thickness during the orbital forming process can be given by the means of FEM. For both materials nodes at about the same position of $r=45 \mathrm{~mm}$ and $y=0 \mathrm{~mm}$, which is the middle of the thickened area, on the upper and bottom side of the tailored blank were analyzed. As for this process, the lower die transmits the tumbling motion resulting in the blank itself receiving the same tumbling motion. This leads to an alternating global movement of the nodes which has to be compensated when analyzing the material flow. By adding the polynomic trend line for each position the global tumbling motion was compensated. The results regarding the material flow are depicted in Figure 17a. At each full cycle, the shown nodal position is in contact with the rotating die. During the ramp up of the tumbling angle in $U_{\mathrm{u}}$ the contact area is continuously decreased as this phase is comparable to upsetting due (a)
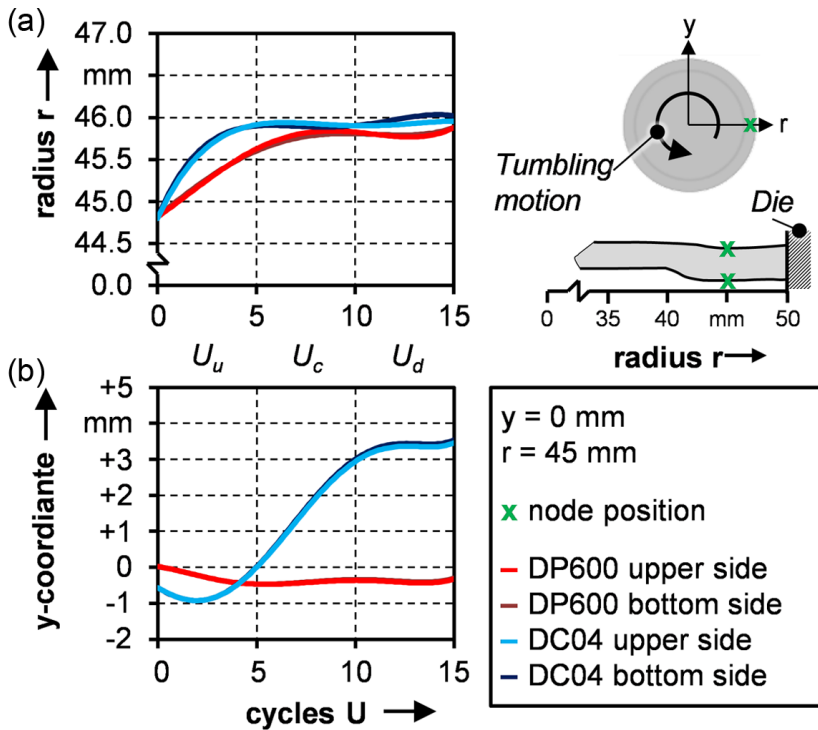

radius $\mathrm{r} \longrightarrow$

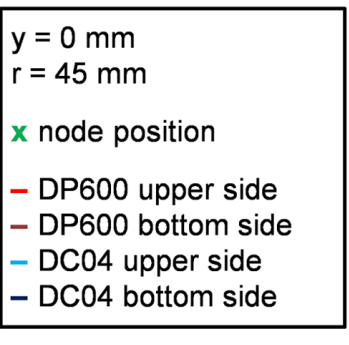

Figure 17. (a) Radial and (b) tangential movement of the material during the process according to the FE-simulation.

to occurring stress states and limited plasticization [36]. The hereby existing spiral tumbling motion results in a strong radial material flow up to $1 \mathrm{~mm}$. For both materials the material is radially transferred to the outside and pressed against the outer die leading to the increase of the sheet thickness with a higher tangential movement of the nodal position for DC04, see Figure $17 \mathrm{~b}$. This can be explained by the better formability of the DC04 compared with the DP600 which has a higher strength. The tangential material flow in negative direction is caused by the dominating upsetting at the beginning of the process, as due to the minimum tumbling angle no contact between the rotating die and workpiece is taking place. Regarding differences between both sides of the tailored blank, no significant difference can be detected. Thus, a near equal material flow through the sheet thickness can be assumed contrary to the so-called "mushroom-effect" from the literature due to the small thickness of the blank and the radial boundary.

After the maximum tumbling has been reached, the radial material flow is primarily replaced by a tangential material flow for DC04 between $U=5$ and $U=10$, see Figure 17. In the phase $U_{\mathrm{c}}$ the tumbling angle is held constant which results in a circular tumbling motion. The material is primarily transferred in tangential direction up to nearly $4 \mathrm{~mm}$. In contrast to the tailored blank out of DC04, the one made from DP600 shows nearly no tangential material flow with a maximum movement of $0.5 \mathrm{~mm}$ opposite to the tumbling motion direction. Considering the measured average sheet thickness this result is consistent. The maximum available process force $F=4,000 \mathrm{kN}$ is not sufficient enough to displace the DP600 material in tangential direction due to the per se higher strength of the material and the additional strain hardening. Thus, the tool is just rolling off on the workpiece surface resulting in a minimal material movement of less than $1 \mathrm{~mm}$. This difference in the tangential material flow between both materials can be explained by the plastic strain and yield stress for the selected nodes in Figure 18. For DC04 the plastic strain increases 
(a)

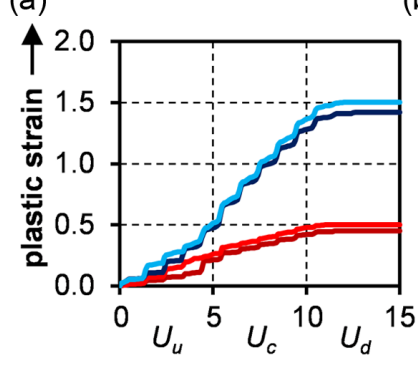

(b)

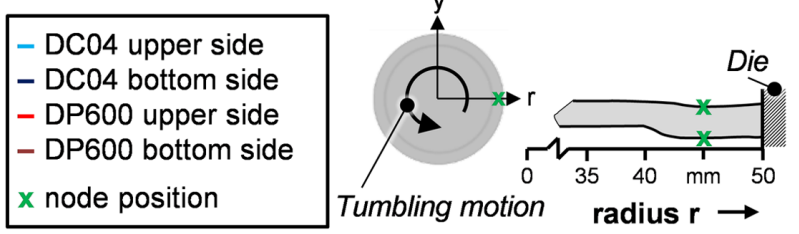

Figure 18. (a) Plastic strain and (b) yield stress for tailored blanks out of DC04 and DP600 during the process according to the FEsimulation.

during $U_{\mathrm{c}}$ at a higher level as for DP600. Thus, less material flow in this area is taking place for DP600 leading to the lower tangential material flow during $U_{\mathrm{c}}$. Regarding the yield stress in Figure 18b, the saturation of the sheet thickening and radial material flow can be explained. For DC04 after finishing the first process phase $U_{\mathrm{u}}$ a saturation of the yield stress can be detected. Considering the material properties presented in Section 3.1, the formability of DC04 has been depleted whereas for DP600 the detected values are still below the maximum ones possible and a continuous increase of the yield stress in $U_{\mathrm{c}}$ can be seen. However, as described above the forming force is not sufficient to displace the material.

Regarding the third process phase $U_{\mathrm{d}}$, the ramp down of the tumbling angle, no significant material flow can be detected as the tailored blanks are by now strain hardened, the forming capacity is depleted and especially for DC04 the die cavity is nearly completely filled. Thus no additional increase of the sheet thickness can be detected. Summarizing, the progression of the geometric dimensions shows and only minimum changes after eight tumbling cycles meaning the orbital forming process could be shortened significantly for future investigations.

In addition to the geometric dimensions of the orbital formed tailored blanks, the strain hardening was analyzed by measuring the Vickers hardness. As each of the three process phases has different influences on the sheet thickness and material flow, the Vickers hardness was measured for a tailored blank after each phase. The results for the DC04 tailored blanks are shown in Figure 19. Regarding the qualitative contour plot, strain hardening of the tailored blank in the thickened outer area after five cycles, the first phase $U_{\mathrm{u}}$, can be detected. This result correlates with the measured sheet thickness which is near its maximum value after five cycles, From then on it is in saturation as well as the yield stress for the presented nodal positions. During the following two phases and ten tumbling cycles no significant differences can be detected by the qualitative contour plot. Besides the higher hardness values in the outer area, a hardness increase compared with the first phase

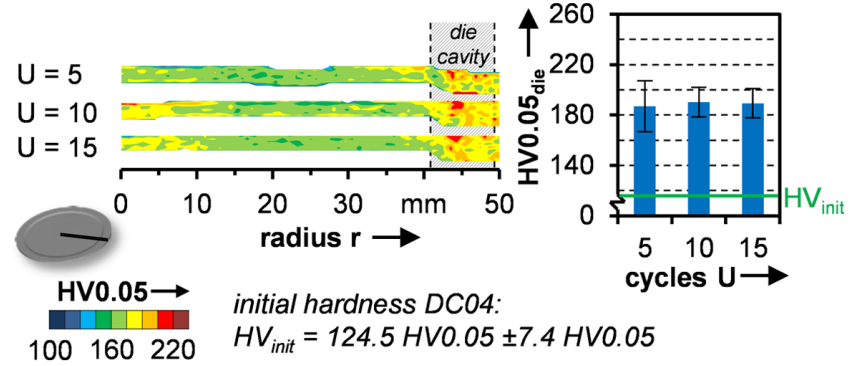

Figure 19. Vickers hardness for DC04 tailored blanks.

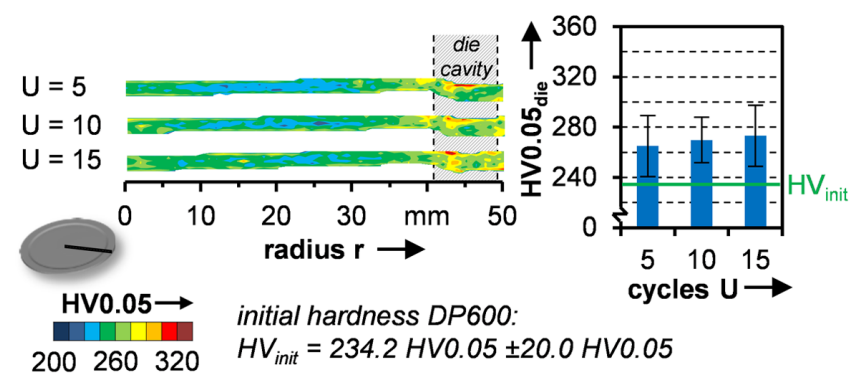

Figure 20. Vickers hardness for DP600 tailored blanks.

towards the center can be detected as well and be explained by the ramp up and ramp down of the tumbling angle. At small tumbling angles the conical upper punch which transmits the press force on the blank leads to an increased pressure of the punch on the blank at a small contact area [36]. The only difference in the tangential material flow between both phases does not result in an additional strain hardening of the tailored blank as the yield stress in the thickened area has reached a saturation level.

Additionally, to the contour plot a quantitative measurement of the hardness values in the die cavity area between $42 \leq r \leq 48 \mathrm{~mm}$ has been implemented. With increasing tumbling cycles, a minimum increase of the average hardness can be detected. However, as the standard deviation for each measuring area superposes the mean values the difference between each value is not significant. The average Vickers hardness in the die cavity area is about $190 \mathrm{HV} 0.05$. Compared with the initial hardness of $124.5 \mathrm{HV} 0.05$ this is an average hardness increase of about $35 \%$. Thus, no distinct statement can be derived regarding the quantitative analysis of the Vickers hardness.

Regarding the tailored blanks out of DP600, the same measurements and calculations were carried out as for DC04. The results are shown in Figure 20 with again the higher values in the thickened outer area. As for the DP600 a lower average sheet thickness and lower tangential material flow has been detected, the average hardness increase in the outer area is lower as well with only about $15 \%$. In absolute numbers, the average Vickers hardness is about 270 HV0.05. As for DC04, no distinct statement can be derived from the quantitative analysis of the Vickers hardness due to the high standard deviation.

Summarizing this section, it could be shown that process adapted semi-finished parts with adapted geometric and mechanical properties can be manufactured by orbital forming. 
Besides the local increase of the sheet thickness in the thickened outer area the tailored blanks are strain hardened up to $35 \%$. Subsequently, these tailored blanks can be applied in SBMF processes for directing the material flow and improving the manufactured components.

\section{Application of the presented solutions}

In this section, the presented solutions, the local adaption of tribological conditions and the application of process adapted semi-finished parts are shown for the SBMF process in Section 4 in order to improve the product quality by specifically controlling the material flow.

\subsection{Tailored surfaces}

This section is aimed to investigate the applicability of tailored surfaces as a method to extend the process limits in SBMF processes. This should be investigated for the two in Section 4 presented SBMF processes to illustrate the functionality of tailored surfaces for two different load conditions. For a comprehensive analysis, the effectiveness of workpiece-sided and a combined workpiece- and tool-sided adaption should be investigated.

\subsubsection{Single-stage process combination of deep drawing and upsetting}

One of the single-stage process combination of deep drawing and upsetting described in Section 4.1 is given by an increased bottom thickening of the cup bottom due to an unintended material flow from the cup wall to the cup bottom. This material flow directly affects the die filling behavior of the gearing cavities. The unintended material flow can be influenced by a local adaption of the friction conditions to impede the material flow.

To verify this approach a numerical feasibility study was used [8]. An impeded material flow from the cup wall into the cup bottom can be reached by a local increase of the friction conditions into the area of the cup bottom seems purposeful. Figure 21 illustrates the numerical results using a locally adapted friction factor in the area of the cup bottom of $m_{\text {bot }}=0.30$ in comparison to the standard definition with a global constant friction factor of $m_{\mathrm{glo}}=0.05$. The friction factor of 0.30 was experimentally determined for blasted surfaces without lubrication [37]. For the global constant friction factor an inhomogeneous rise of the sheet thickness is detectable due to a gradient in friction shear stress. For the locally adapted model no thickening can be detected because the material flow into the cup bottom is restrained. Additionally, the improved control of the material flow is observable by an increased cup height due to more material in the area of the cup wall. Based on these numerical results it can be stated that an increase of the friction conditions in the area of the cup bottom should extend the process limits of the single-stage process combination of deep drawing and upsetting.

Furthermore, the experimental verification of the numerical results should be presented. As shown in Section 5.1 blasted

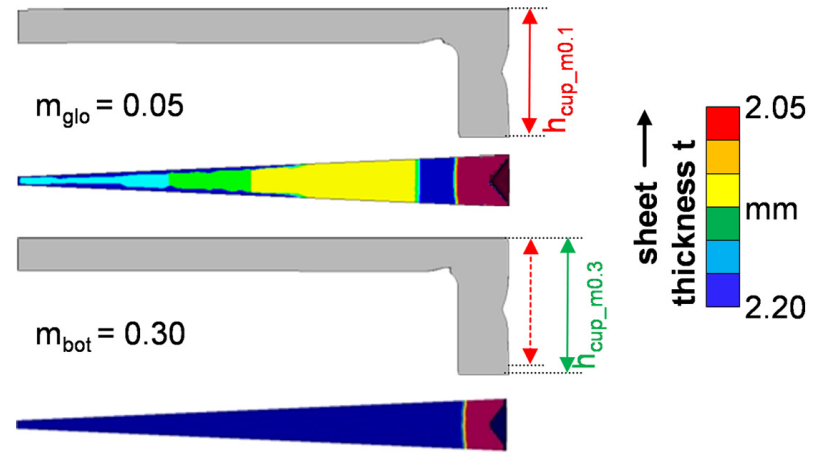

Figure 21. Results of the numerical feasibility study for global constant friction conditions $m_{\text {glo }}$ compared to locally adapted friction conditions $m_{\text {bot }}$. (a)

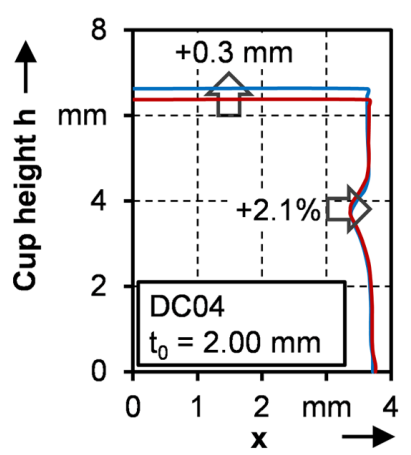

(c)

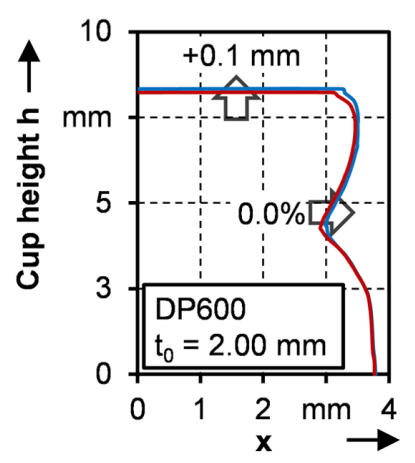

(b)

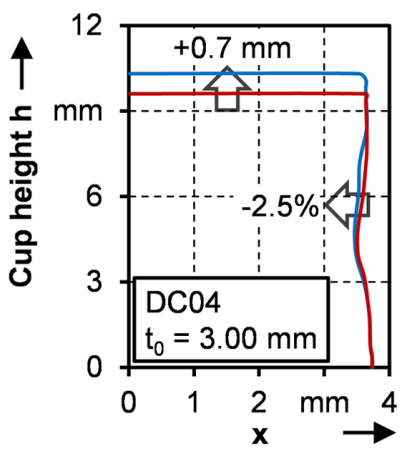

Figure 22. Cup height and die filling for tailored surfaces and conventional blanks of (a) DC04 $t_{0}=2.0 \mathrm{~mm}$ (b) DC04 $t_{0}=3.0 \mathrm{~mm}$ and (c) DP600 $t_{0}=2.0 \mathrm{~mm}$ [38].

workpiece surfaces are an appropriate approach to increase friction. Thus, the application of blanks, which are blasted in the area of the cup bottom, should result in improved results regarding geometrical accuracy with respect to an improved die filling.

Figure 22 illustrates the results of using locally blasted blanks out of DC04 with an initial sheet thickness $t_{0}=2.0 \mathrm{~mm}$ and $t=3.0 \mathrm{~mm}$ and DP600 with an initial sheet thickness $t_{0}=2.0 \mathrm{~mm}$. The process conditions are described in Section 4.1. The diagram in Figure 22 reveals that the cup height of all investigated parts could be increased by the use of locally blasted workpieces. Thus, more material remains 
in the area of the gearing. For DC04 with a sheet thickness of $t_{0}=2.0 \mathrm{~mm}$ an increase of $0.3 \mathrm{~mm}$ is obtained. By analyzing DC04 with a sheet thickness of $t_{0}=3.0 \mathrm{~mm}$ the increase of the cup height amounts $0.7 \mathrm{~mm}$. DP600 shows an increase of $0.1 \mathrm{~mm}$. By analyzing the die filling behavior of DP600 and DC04 with a sheet thickness of $t_{0}=2.0 \mathrm{~mm}$ an improvement of $2.1 \%$ for DC04 is obtainable. For DP600 no improvement was detected. In contrast the die filling of DC04 with an initial sheet thickness $t_{0}=3.0 \mathrm{~mm}$ is decreased by $2.5 \%$. The results for DP600 and the decreased die filling for DC04 with an initial sheet thickness of $t_{0}=3.0 \mathrm{~mm}$ can be explained by the used upsetting force of $F=1,000 \mathrm{kN}$. This force was chosen for all three types of workpieces to guarantee comparability of the results. The force is optimized to the forming of DC04 with initial sheet thickness of $t_{0}=2.0 \mathrm{~mm}$. For the forming of DC04 with initial sheet thickness $t_{0}=3.0 \mathrm{~mm}$ and DP600 higher forces are needed. This is due to the increase of material volume for DC04 $t_{0}=3.0 \mathrm{~mm}$ and the twice as higher yield strength of DP600. It can be expected that an increase of the upsetting force for these two types of workpieces leads to an increased die filling of the workpieces made out of DC04 with $t_{0}=3.0 \mathrm{~mm}$ and DP600.

All in all, it can be stated, that a local increase of the friction in the area of the cup bottom leads to an increased die filling and a reduced thickening of the cup bottom. Thus, locally adapted tribological conditions are an appropriate method to extend the process limits of this kind of single-stage process combination of deep drawing and upsetting.

\subsubsection{Forward extrusion}

To illustrate the effectiveness of tailored surfaces the application of locally adapted tribological conditions should additionally be shown for different load conditions using a forward extrusion process of teeth, with varying geometries. The main process limit of this SBMF process is given by an insufficient die filling of the rectangular and triangular functional elements because of the material flow, which is directed radially into the middle area of the component. Thus, this kind of material flow needs to be restrained. A possible method is given by the increase of the friction conditions in the middle area of the component.

To verify this assumption in a first step a numerical feasibility study was used. The investigation is comparable to the approach for the single-stage process combination of deep drawing and upsetting described in Section 6.1.1. As workpiece material DC04 with an initial sheet thickness of $2.0 \mathrm{~mm}$ was used. The results are shown in Figure 23. The numerical model of the process was simulated with locally adapted friction factors $m_{\text {loc. }}$ All contact areas, except between die and workpiece, were simulated with an increased friction factor of 0.3 . This friction factor was determined for blasted surfaces without lubrication [37]. Between die and workpiece the friction factor was kept to a lower value of 0.12 to support the material flow into this area. The friction factor of 0.12 was determined for blasted surfaces in combination with the lubricant Beruforge 150 DL [37]. As a reference, the process was simulated using a global constant friction factor $m_{\mathrm{glo}}$ of 0.12 between workpiece and die, see Figure 20. The local adaption
Rectangular element

Triangular element

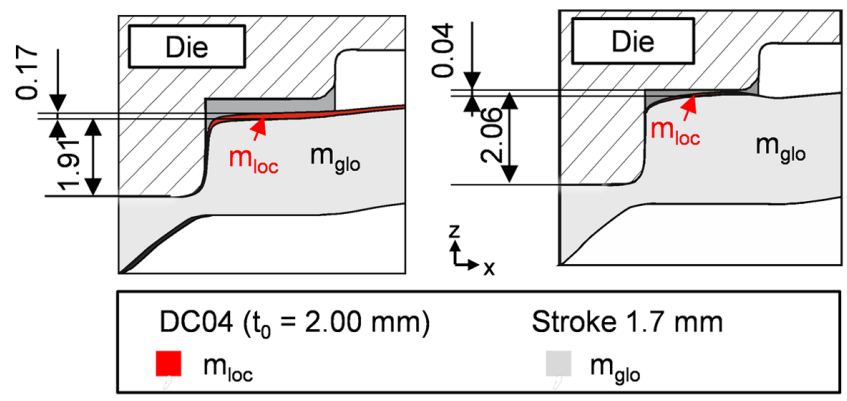

Figure 23. Results of the numerical feasibility study [39]. (a)

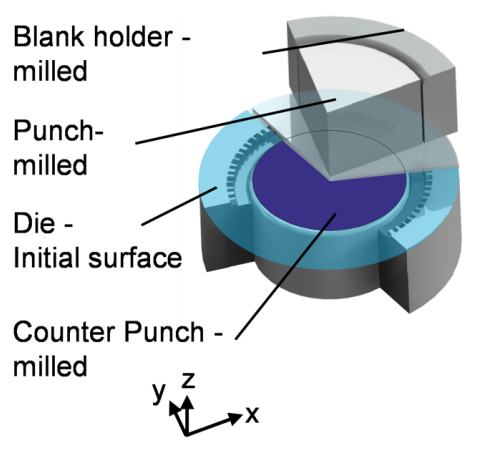

(b)

Contact area Punch/ Blank holder

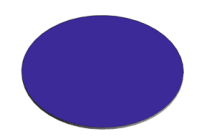

Contact area Die/ Counter Punch

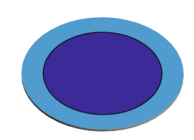

No surface adaption

Application of tailored surfaces

Figure 24. Application of tailored surfaces for (a) tool components and (b) workpiece [39].

of the friction leads to an increase of the element height for the rectangular and triangular element. Thus, increasing the friction in all contact areas, except between die and workpiece, leads to an increased die filling for both functional elements and thus an extension of the process limits.

The numerical investigation illustrates the principle feasibility. To determine the concrete effect of locally adapted tribological conditions on the process result an experimental investigation is necessary. Based on the knowledge of the numerical feasibility study, the experimental verification of this result should be shown within this section. For the experimental investigation the workpieces are made out of DC04 with an initial sheet thickness $t_{0}$ of $2.00 \mathrm{~mm}$. Beruforge $150 \mathrm{DL}$ was used as lubricant. As an increase of the friction conditions is needed, the surface adaption which leads to the highest possible increase in friction conditions presented in Section 5.1 are chosen. Thus, a combination of milled tool and blasted workpiece surfaces is used for the investigation. As the surface adaption needs to be similar to the numerical feasibility study the surface of the punch, the blank holder and the counter punch are adapted by high-feed milling. The workpiece is blasted in the respective contact area to the three milled tool components. The adaptions are illustrated in Figure 24.

Figure 25 compares the results of three blanks using local surface modifications of tool and workpiece TS to three conventional blanks, so-called reference blanks RB, without 


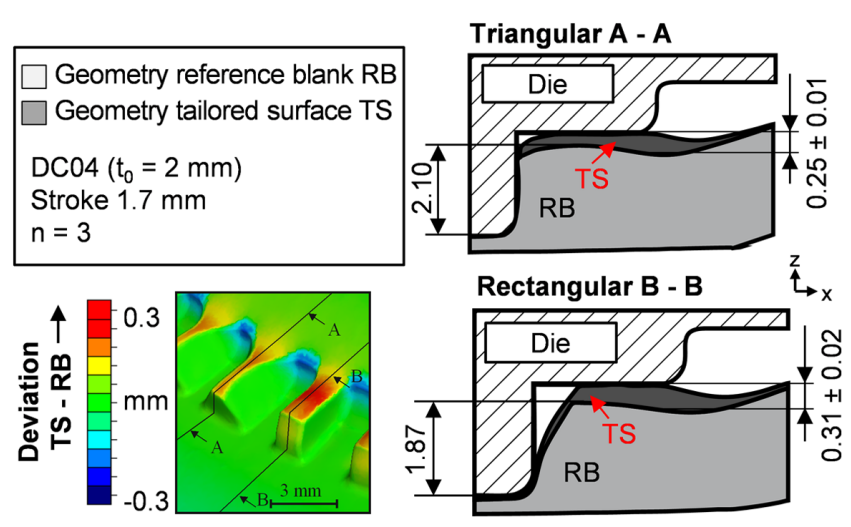

Figure 25. Results of experimental verification of the effectiveness of combined workpiece-sided abrasive blasting and tool-sided milling [39].

a modification of tool and blank surface. The local adaption of the friction conditions using tailored surfaces leads to a significant increase of the height for both types of functional elements. Thus, more material flows into the cavities and increases the heights of the functional elements. The increase of the maximum height of the triangular element amounts $0.25 \pm 0.01 \mathrm{~mm}$. For the rectangular element the height is increased by $0.31 \pm 0.02 \mathrm{~mm}$.

Thus, it can be stated that using locally adapted tribological conditions leads to an increased die filling for both functional elements due to an improved control of the material flow. This indicates that using tailored surfaces improves the product quality and extends the process limits of this kind of SBMF process.

\subsection{Tailored blanks}

\subsubsection{Deep drawing and upsetting}

The application of tailored blanks in the process combination of deep drawing and upsetting aims at improving geometrical and mechanical part properties while enhancing the lightweight construction potential by utilizing the process adapted material pre-distribution and mechanical properties. The aim of the material pre-distribution is to prevent buckling of the cup wall and enable an enhanced die filling. Furthermore, the modified mechanical properties are expected to improve the control of the material flow. As evaluation criteria for geometrical properties the die filling, the wall height and the sheet thickness in the bottom are adduced. Additionally, the radius of folding and the depth of folding and grooving are investigated. The folding radius is an indicator for occurring material flow into the bottom of the cup as the radius decreases with increasing material flow in the bottom. The effect is shown in Figure 26. The depth of folding and grooving show how distinctive the failure modes occur.

The tailored blanks were formed by the orbital forming process presented in Section 5.2. The forming force is set to $F=1,000 \mathrm{kN}$ and the radius of the drawing punch is $r=1 \mathrm{~mm}$. The tailored blanks are positioned with the thickening on the upper side.

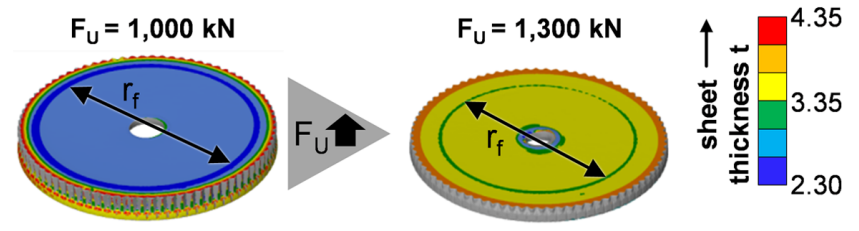

Figure 26. Dependence of the folding radius of the forming force [8].

(a)

(b)

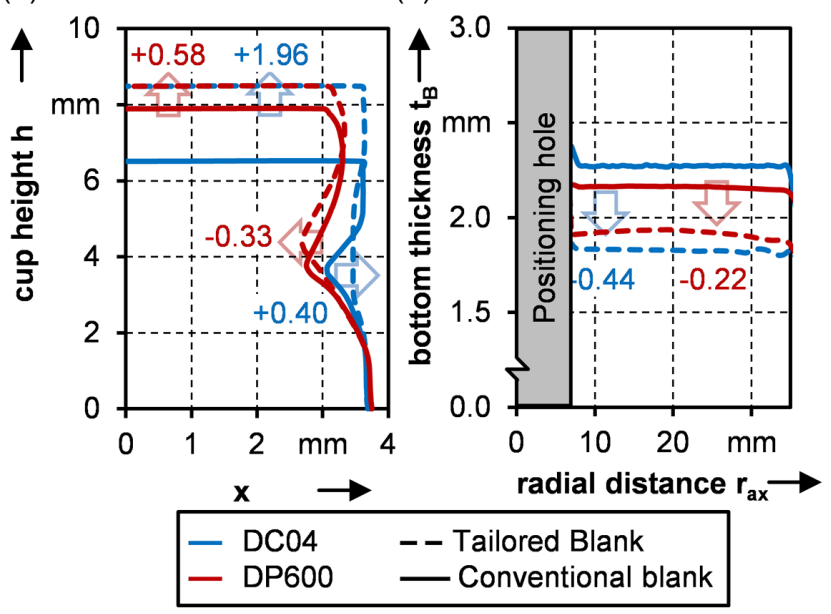

Figure 27. Potential of orbital formed tailored blanks in SBMF to improve (a) cup wall and (b) reduce bottom thickness.

The geometrical properties are decisive for the functionality of the geared parts. For the DC04 the cup wall height of the part manufactured from a conventional semi-finished product amounts $6.51 \mathrm{~mm}$, see Figure 27a. The sheet thickness in the bottom of the cup is $2.27 \mathrm{~mm}$ and thereby $0.27 \mathrm{~mm}$ higher than the initial sheet thickness. The radius of the folding is $36.27 \mathrm{~mm}$, the depth of the folding is $0.61 \mathrm{~mm}$ and the depth of the grooving is $0.39 \mathrm{~mm}$. For the application of an orbital formed tailored blank an improved filling of the gear cavity up to $0.40 \mathrm{~mm}$ can be achieved with an increased cup wall height of $1.96 \mathrm{~mm}$ up to $8.48 \mathrm{~mm}$. The sheet thickness in the bottom is $1.76 \mathrm{~mm}$ and thereby significantly lower than the initial sheet thickness of $t_{0}=2.0 \mathrm{~mm}$, as shown in Figure 27b. Due to the reduced material flow into the bottom the folding radius is $0.27 \mathrm{~mm}$ higher, while the folding and grooving depth is decreased by $0.06 \mathrm{~mm}$ and $0.27 \mathrm{~mm}$ respectively. For DP600 the application of tailored blanks also allows the improvement of the geometrical properties of the parts. The wall height of the part manufactured from the orbital formed tailored blank amounts to $7.89 \mathrm{~mm}$ and is $0.58 \mathrm{~mm}$ higher than the height of the part manufactured from plane sheet. The folding radius is $37.17 \mathrm{~mm}$ compared to $36.61 \mathrm{~mm}$ and the depth of folding and grooving is decreased by $0.21 \mathrm{~mm}$ and $0.23 \mathrm{~mm}$ compared to the application of a conventional plane blank. The application of tailored blanks enables an improvement of the geometric part properties for both materials. Applying the DC04 tailored blank, a nearly complete filling of the gear cavities is possible. A further enhancement can 
(a)

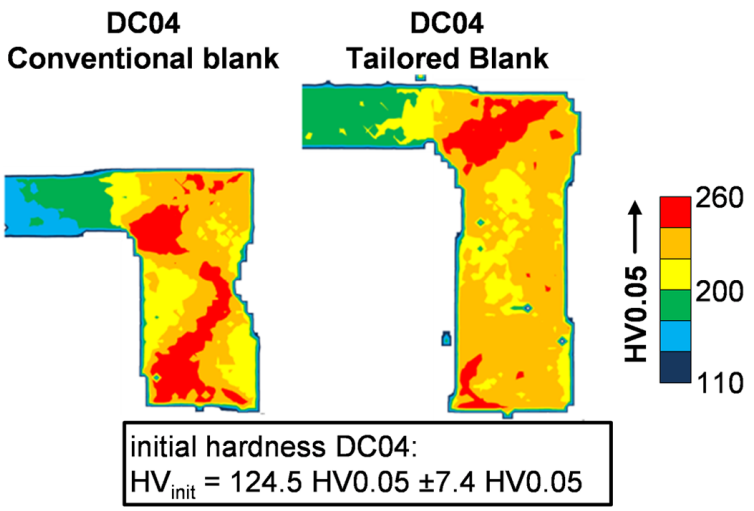

(b)
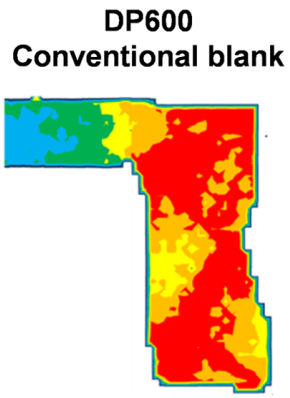

DP600

Tailored blank

initial hardness DP600:

$\mathrm{HV}_{\text {init }}=234.2 \mathrm{HVO} .05 \pm 20.0 \mathrm{HV} 0.05$

Figure 28. Vickers hardness of cup walls for conventional blanks and tailored blanks out of (a) DC04 and (b) DP600.

be achieved by adapting the tailored blank layout. Comparing both materials in general, the improvement for high-strength DP600 is lower than for DC04 due to lower material pre-distribution of the tailored blanks manufactured in the force-bound orbital forming process.

The mechanical properties are crucial to the load capacity and the durability of the parts during application. They were evaluated by comparing the Vickers hardness in the bottom and in the wall area and the homogeneity of the hardness, see Figure 28. For DC04 the mean value of the hardness measured in the wall area is $216 \mathrm{HV} 0.05$ for a conventional semi-finished product and $218 \mathrm{HV} 0.05$ for the orbital formed tailored blank. In the bottom of the cup the hardness amounts to $166 \mathrm{HV} 0.05$ and $172 \mathrm{HV} 0.05$ respectively. For DP600 the application of orbital formed tailored blanks leads to an increase of the hardness in the wall from $338 \mathrm{HV} 0.05$ up to $343 \mathrm{HV} 0.05$ and from $254 \mathrm{HV} 0.05$ up to $261 \mathrm{HV} 0.05$ in the bottom of the cup. Furthermore, the application of tailored blanks leads to an increased homogeneity of the hardness distribution. As the material volume remains constant, the geometrical values interdepend and also determine the mechanical properties of the part. Therefore, the varying properties of the tailored blanks have to be considered. Although the material pre-distribution for DP600 is low compared to DC04 the sheet thickness in the bottom area of the cup is lower than the initial sheet thickness. The positive effects on the parts properties are observed for both workpiece materials. The mild deep drawing steel shows better geometrical properties due to a (a)

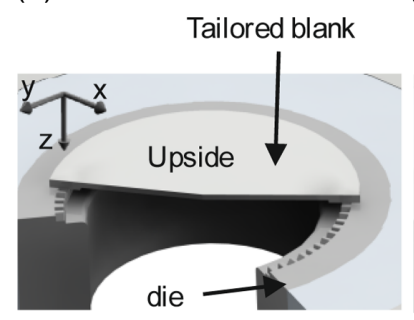

(b)

Outer area with increased sheet thickness

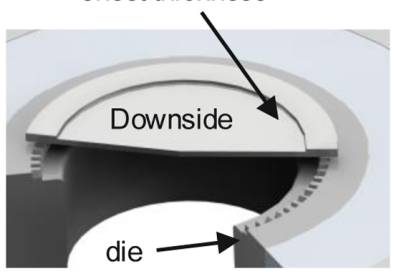

Figure 29. Lay in strategies for orbital formed tailored blanks with (a) upside orientation and (b) downside orientation [12].

higher formability whereas the dual-phase steel has a higher load capacity due to a significantly higher initial hardness.

Summarizing, the application of tailored blanks in the combined deep drawing and upsetting process has led to an improved quality of the manufactured components. The unwanted material flow in the cup bottom has been decreased, the cup wall height increased and the filling of the geared cavities has been improved as well.

Besides this process, the same tailored blanks were applied in another SBMF process which is the forward extrusion process presented in Section 4.2.

\subsubsection{Forward extrusion}

As in the upsetting process, tailored blanks of varying sheet thickness can also be used to enhance the forming limits of forward extrusion processes. However, in contrast to upsetting, the mechanism of action is different. Forward extrusion can only be used to form functional elements from a flat surface and in direction of the blank normal. Hence, a central process limit regarding the elements dimension is given by the maximum punch stroke possible, which in turn is dependent on the initial sheet thickness. Furthermore, in-plane material flow increases with decreasing sheet thickness during the forming operation. From this perspective, form filling can be increased by using a blank of high initial thickness and a punch stroke that is also as high as possible. However, due to lightweight considerations the use of blanks of generally higher thickness is not constructive. Since a high thickness is only necessary in the forming area around the die cavities, tailored blanks can be a useful approach to accomplish better elemental forming without increasing the part weight by meaningful amounts. This concept has been investigated recently in reference [10] with tailored blanks and in the forward extrusion process described in Section 4.2. In this case, reference blanks of $t_{0}=2 \mathrm{~mm}$ initial thickness have been compared to the orbital formed tailored blanks presented in Section 5.2. Figure 29 shows both investigated orientations of the blank on the forward extrusion die. The thickened outer area of the blank provides additional material only in the forming area above the cavities. The investigation has proven that the blank orientation did not show any influence on the achievable element height [10].

Figure 30 depicts the results on the maximum element height comparing DC04 reference and orbital formed tailored blanks. All experiments have been carried out until the same 


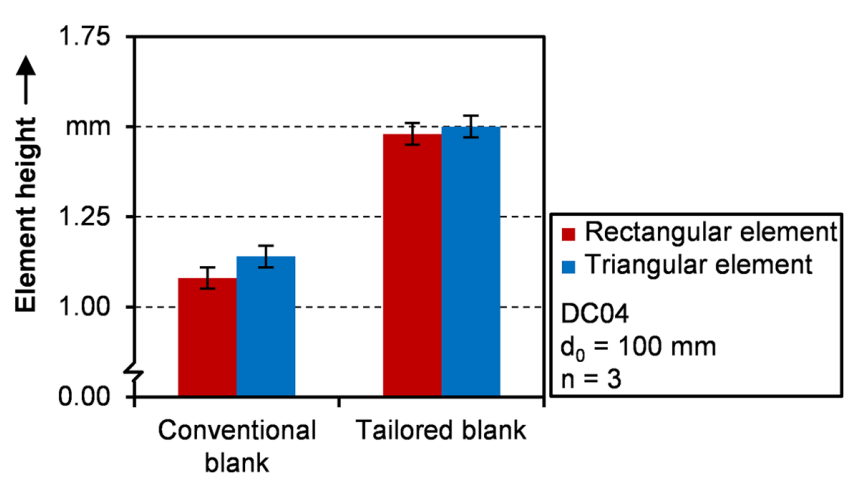

Figure 30. Blank height of conventional blanks and tailored blanks out of DC04 [10].
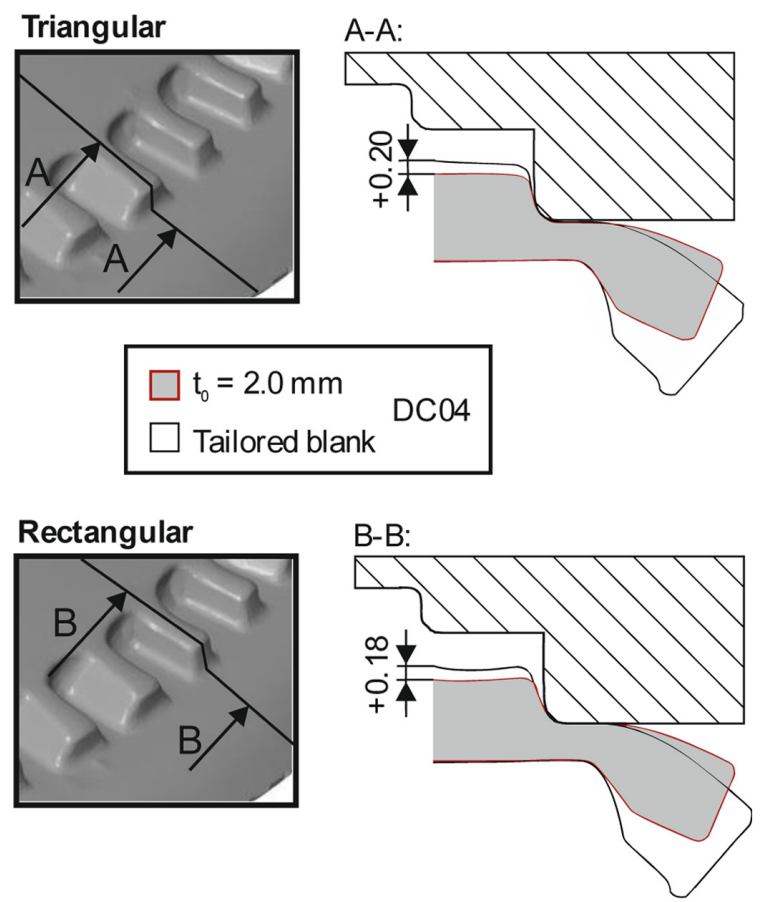

Figure 31. Cut display for reference and orbital formed tailored blanks out of DC04 [10].

remaining sheet thickness of $1.1 \mathrm{~mm}$ in the area between the elements has been reached.

As is evident, element height can be increased significantly between 0.4 and $0.46 \mathrm{~mm}$ depending on the element shape. This equals an improvement of up to $37 \%$ in case of the rectangular shape. The improvement is also visualized in Figure 31, which shows a cut display through the rectangular and triangular element for two exemplary DC04 blanks. As is demonstrated, both the triangular and the rectangular elements show an increase in maximum height of $0.20 \mathrm{~mm}$ and $0.18 \mathrm{~mm}$ respectively.

In order to ensure the transferability of the results, blanks consisting of DP600 have been investigated in addition. Figure 32 depicts the results on maximum blank heights and reveal that similar improvements as in the case of DC04 can be ascertained with higher strength steels. In fact differences

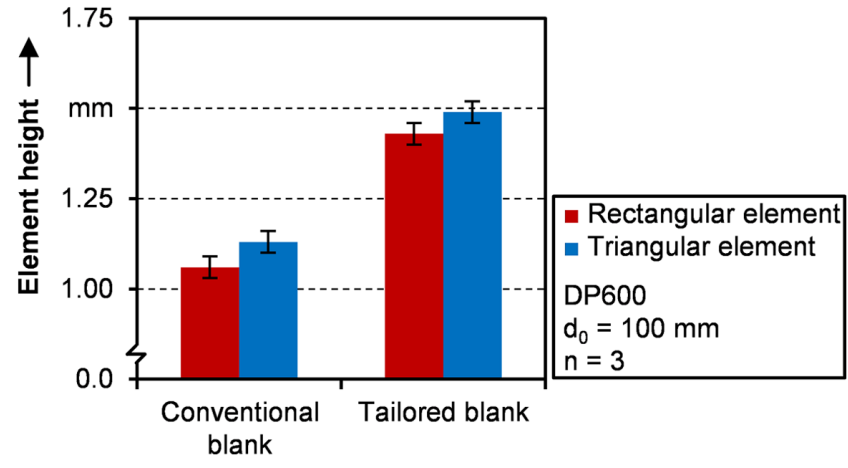

Figure 32. Blank height of conventional blanks and tailored blanks out of DP600 [10].

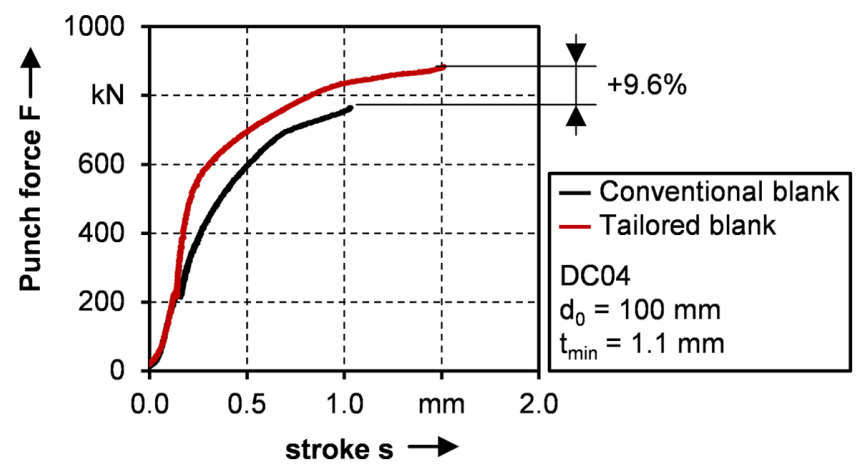

Figure 33. Comparison of punch force for conventional blanks and tailored blanks out of $\mathrm{DC} 04$ at remaining sheet thickness of $t=1.1 \mathrm{~mm}$ [10].

between the two materials are small $(\Delta h<0.05 \mathrm{~mm})$ and can be contributed to differences in initial rim height that are a result of the manufacturing process, as has been described in Section 5.2.

It can be expected that the locally differing hardness of the tailored blanks does exert an influence on the results presented above. Current research [10] indicates that this is not the case, however further research is needed to clarify this aspect.

A disadvantage of tailored blanks is the higher demands on punch force if compared at the same remaining sheet thickness in the area between the cavities, see Figure 33. For DC04 in comparison to the conventional blank, the necessary process force is about $10 \%$ higher at the same stroke if tailored blanks are used. The higher press force and higher hardness of the tailored blanks increases the tool loads. Thus, and especially for high-strength steels, it has to be considered what press stroke is necessary and possible for forming the functional elements. The small discontinuity at about $200 \mathrm{kN}$ can be explained by an additional small increase of pressure by the hydraulic press.

This circumstance is a direct result of the manufacturing process of the tailored blanks. As has been demonstrated in Section 5.2, orbital formed blanks generally possess a higher hardness distribution, especially in the outer edge of the blank. Figure 34 demonstrates this by means of a comparison between the hardness distribution for the reference and for the tailored 


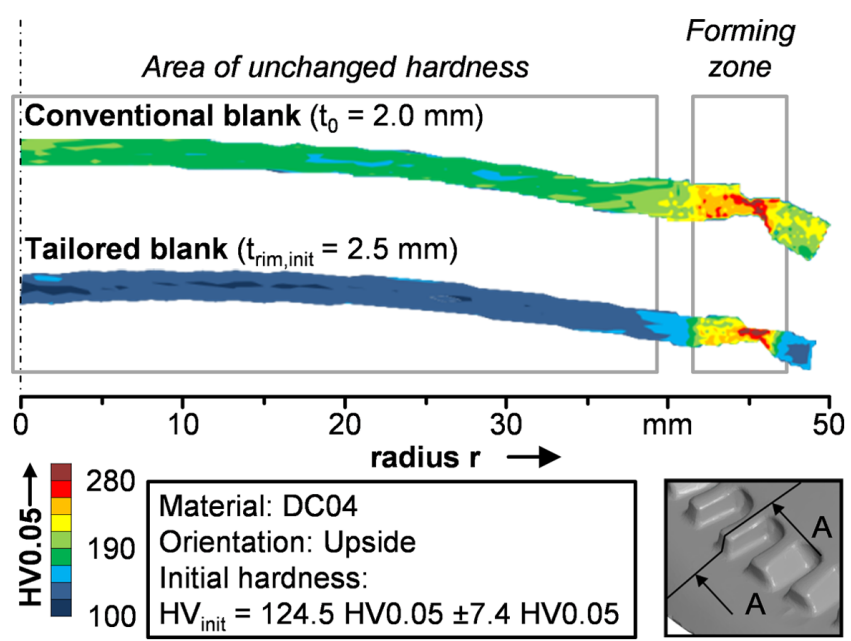

Figure 34. Vickers hardness of conventional blanks and tailored blanks out of DC04 [10].

blank at the end of the forward extrusion process. It is evident that from the picture that the mean values of the resulting hardness in the forming area are still higher for the tailored blank, even at the process end. The higher material displacement when forming the tailored blanks leads to a higher bulging of the tailored blanks.

Summarizing, the application of tailored blanks can be used for controlling the material flow in sheet-bulk metal forming processes. Considering lightweight aspects, their application leads to an improved forming of functional elements and thus is a promising approach for further development.

\section{Summary and outlook}

Saving resources is a key priority in today's economy. For the manufacturing industry this can be achieved by improving the material efficiency and shortening the process chains. Applying bulk forming operations on sheet metals is a promising approach and enables the manufacturing of complex lightweight components with integrated functional elements. However, new challenges within these processes arise. Due to an increased complexity of these components with locally varying forming zones, controlling the material flow is essential for ensuring the request component quality. For the two SBMF processes presented in this paper, a single stage process combination of deep drawing and upsetting and a forward extrusion process, the challenges and necessity for a controlled material flow are presented. Subsequent two innovative solutions for controlling the material flow are shown. The local adaption of the tribological conditions using tailored surfaces, and the application of tailored blanks which are process adapted semi-finished parts with defined geometrical and mechanical properties. Both solutions were applied in the presented SBMF-processes resulting in an improvement of the components properties by a better forming of the integrated functional elements. Comparing both solutions, a higher improvement for the functional elements in terms of the differences in geometric dimensions can be achieved and primarily explained by an increased material volume of about $25 \%$ in the relevant area.

Regarding current and future research within this topic, the focus will be on investigating the complex process chain from the initial blank to the forming of tailored blanks respectively the application of tailored surfaces and the subsequent manufacturing of components with functional elements. For these investigations, experimental as well as numerical methods will be used.

Acknowledgements. This work was supported by the German Research Foundation (DFG) within the scope of the Transregional Collaborative Research Centre on sheet-bulk metal forming (CRC/TR 73) in the subprojects A1, A2 and C1.

\section{References}

1. J.M. Allwood, J.M. Cullen, Sustainable materials with both eyes open, Uit Cambridge Ltd., Cambridge, 2011.

2. ZF Friedrichshafen AG, Weight-Saving ZF Technology for the Chassis, https://www.zf.com/china/media/en_cn/china/ regional_content_china/news_cn/auto_shanghai/press_release/ tx05_autoshanghai15_zf_lightweight_design_en.pdf [October 19, 2015].

3. M. Merklein, A.E. Tekkaya, A. Brosius, S. Opel, J. Koch, Overview on sheet-bulk metal forming processes, Proceedings of the 10th International Conference on Technology of Plasticity, Aachen, Germany, 2011, pp. 1109-1114.

4. M. Merklein, J.M. Allwood, B.-A. Behrens, A. Brosius, H. Hagenah, K. Kuzman, K. Mori, A.E. Tekkaya, A. Weckenmann, Bulk forming of sheet metal, Annals of the CIRP 61 (2012) 725-745.

5. M. Merklein, J. Koch, S. Opel, T. Schneider, Fundamental investigations on the material flow at combined sheet and bulk metal forming processes, Annals of the CIRP 60 (2011) 283-286.

6. DIN 8582, Manufacturing processes forming - classification, subdivision, terms and definitions, alphabetical index, Beuth Verlag GmbH, Berlin, Germany, 2003.

7. M. Merklein, H. Hagenah, T. Schneider, Sheet-bulk metal forming processes - state of the art and its perspectives, in: R. Kolleck (Ed.), TTP 2013 - Tools and Technologies for Processing Ultra High Strength Materials, Verlag der TU Graz, Graz, Austria, 2013, pp. 197-204.

8. T. Schneider, U. Vierzigmann, M. Merklein, Analysis of varying properties of semi-finished products in sheet-bulk metal forming of functional components, AIP Conference Proceedings 1567 (2014) 930-933.

9. T. Schneider, M. Merklein, Manufacturing of geared sheet metal components by a single-stage sheet-bulk metal forming process, in: D. Dimitrov, C. Schutte (Eds.), Proc. Conf. Competitive Manufacturing, Stellenbosch University Publishing, Stellenbosch, South Africa, 2013, pp. 177-182.

10. D. Gröbel, P. Hildenbrand, U. Engel, M. Merklein, Influence of tailored blanks on forming of cold forged functional elements in a sheet bulk metal forming process, in: Stahl-Institut VDEh (Ed.), Proceedings METEC \& 2nd ESTAT, Steel institute VDEh, Düsseldorf, Germany, 2015, pp. 01001 1-12.

11. M. Merklein, J. Koch, T. Schneider, S. Opel, U. Vierzigmann, Manufacturing of complex functional components with variants 
by using a new metal forming process - sheet-bulk metal forming, International Journal of Material Forming 3 (2010) 347-350.

12. D. Gröbel, J. Koch, U. Vierzigmann, U. Engel, M. Merklein, Investigations and approaches on material flow of non-uniform arranged cavities in sheet bulk metal forming processes, Procedia Engineering 81 (2014) 401-406.

13. N. Bay, A. Azushima, P. Groche, I. Ishibashi, M. Merklein, M. Morishita, T. Nakamura, S. Schmid, M. Yoshida, Environmentally Benign Tribo-systems for metal forming, Annals of the CIRP 59 (2010) 760-780.

14. Z.G. Wang, Y. Yoshikawa, K. Osakada, A new forming method of solid bosses on a cup made by deep drawing, Annals of the CIRP 62 (2013) 291-294.

15. N. Bay, T. Nakamura, S. Schmid, Green lubricants for metal forming, in: Proceeding of the 4th International Conference on Tribology in Manufacturing Processes, Nice, 2010, pp. 5-28.

16. S. Twardy, O. Riemer, E. Brinksmeier, Tribology of micro milled surfaces, Key Engineering Materials 447-448 (2010) 681-684.

17. R. Hense, P. Kersting, U. Vierzigmann, M. Löffler, D. Biermann, M. Merklein, C. Wels, High-feed milling of tailored surfaces for sheet-bulk metal forming tools, Production Engineering 9 (2014), 215-223, DOI: 10.1007/s11740-0140597-0.

18. H. Hetzner, W. Tillmann, S. Tremmel, J. Herper, Tribologische Dünnschichten für die Blechmassivumformung, 1. Workshop Blechmassivumformung, Meisenbach-Verlag, Bamberg, Germany, 2011, pp. 139-158.

19. M. Sedlacek, B. Podgornik, J. Vizintin, Influence of surface preparation on roughness parameters, friction and wear, Wear 266 (2009) 482-487.

20. U. Vierzigmann, M. Merklein, U. Engel, Tailored surfaces in sheet-bulk metal forming, Proceeding of the 4th International Conference on Tribology in Manufacturing Processes 2 (2010) 541-550.

21. A. Zabel, T. Surmann, A. Peuker, Surface structuring and tool path planning for efficient milling of dies, in: 7th International Conference on High Speed Machining Proceedings, Bamberg, 2008, pp. 155-160.

22. H.E. Friedrich, Leichtbau in der Fahrzeugtechnik, Springer Vieweg, Wiesbaden, Germany, 2013.

23. Z. Marciniak, A rocking-die technique for cold-forming operations, Machinery and Production Engineering 117 (1970) 792-797.

24. Heinrich Schmid Maschinen- und Werkzeugbau AG, Umformtechnik 2 (2006) 28-31.

25. J.J. Sheu, C.H. Yu, The cold orbital forging die and process design of a hollow-ring gear part, Proceedings of the 35th International Matador Conference 6 (2007) 111-114.
26. J.R. Maicki, Orbital forging, Metallurgia and Metal Forming (1977) 265-269.

27. K. Lange, Umformtechnik, Handbuch für Industrie und Wissenschaft, Band 2: Massivumformung. 2nd ed., Springer-Verlag, Berlin, Germany, 1988.

28. X. Han, L. Hua, Investigation on contact parameters in cold rotary forging using a 3D FE method, International Journal of Advanced Manufacturing Technology 62 (2012) 1087-1106.

29. P.M. Standring, Characteristics of rotary forging as an advanced manufacturing tool, Proceedings of the Institution of Mechanical Engineers Part B 215 (2001) 935-945.

30. H.-K. Oh, S. Choi, A study on center thinning in the rotary forging of a circular plate, Journal of Materials Processing Technology 66 (1997) 101-106.

31. X. Han, L. Hua, Comparison between cold rotary forging and conventional forging, Journal of Mechanical Science and Technology 23 (2009) 2668-2678.

32. G. Liu, S.J. Yuan, Z.R. Wang, D.C. Zhou, Explanation of the mushroom effect in the rotary forging of a cylinder, Journal of Materials Processing Technology 151 (2004) 178-182.

33. S. Opel, Herstellung prozessangepasster Halbzeuge mit variabler Blechdicke durch die Anwendung von Verfahren der Blechmassivumformung, Meisenbach Verlag, Erlangen, Germany, 2013.

34. P. Hildenbrand, R. Schulte, M. Merklein, New process strategies to manufacture tailored blanks out of DP600 by orbital forming, Applied Mechanics and Materials 794 (2015) 144-151.

35. M. Merklein, P. Hildenbrand, T. Schneider, Application of process adapted semi-finished parts for the production of thinwalled components via sheet-bulk forming, in: R. Kawalla (Ed.), AutoMetForm/SFU 2014, ACATRAIN e.V, Freiberg, Germany, 2014, pp. 58-66.

36. M. Merklein, R. Plettke, S. Opel, Orbital forming of tailored blanks from sheet metal, Annals of the CIRP 61 (2012) 263-266.

37. U. Vierzigmann, J. Koch, M. Merklein, U. Engel, Material flow in sheet-bulk metal forming, Key Engineering Materials 504-506 (2012) 1035-1040.

38. M. Löffler, T. Schneider, U. Vierzigmann, U. Engel, M. Merklein, Locally adapted tribological conditions as a method for influencing the material flow in sheet-bulk metal forming processes, Key Engineering Materials 639 (2015) 267-274.

39. M. Löffler, D. Gröbel, U. Engel, K. Andreas, M. Merklein, Analysis of effectiveness of locally adapted tribological conditions for improving product quality in sheet-bulk metal forming, Applied Mechanics and Materials 794 (2015) 81-88.

Cite this article as: Merklein M, Lechner M, Gröbel D, Löffler M, Schneider T, Schulte R \& Hildenbrand P: Innovative approaches for controlling the material flow in sheet-bulk metal forming processes. Manufacturing Rev. 2016, 3, 2. 